Supporting Information

\title{
Photoredox/Nickel Dual Catalytic Cross-Coupling of Potassium Thiomethyltrifluoroborates with Aryl and Heteroaryl Bromides
}

\author{
Katherine Townsend, Malcolm P. Huestis, and John C. Tellis* \\ Discovery Chemistry, Genentech, Inc., 1 DNA Way, South San Francisco, California, 94080, United States
}

*To whom correspondence should be addressed. Email: tellisj@gene.com 


\section{${ }^{1} \mathrm{H}$ and ${ }^{13} \mathrm{C}$ Spectra of Characterized Compounds}

${ }^{1} \mathrm{H}$ NMR of Potassium trifluoro((phenylthio)methyl)borate $\mathbf{3 3}$

${ }^{13} \mathrm{C}\left\{{ }^{1} \mathrm{H}\right\}$ NMR of Potassium trifluoro((phenylthio)methyl)borate $\mathbf{1} \quad$ S3

${ }^{1}$ H NMR of Potassium ((tert-butylthio)methyl)trifluoroborate $2 \quad$ S4

${ }^{13} \mathrm{C}\left\{{ }^{1} \mathrm{H}\right\}$ NMR of Potassium ((tert-butylthio)methyl)trifluoroborate $\mathbf{2} \quad$ S4

${ }^{1} \mathrm{H}$ NMR of Potassium (((3-chlorophenyl)thio)methyl)trifluoroborate $3 \quad$ S5

${ }^{13} \mathrm{C}\left\{{ }^{1} \mathrm{H}\right\}$ NMR of Potassium (((3-chlorophenyl)thio)methyl)trifluoroborate $3 \quad$ S5

${ }^{1} \mathrm{H}$ NMR of Potassium (((3,5-dimethoxyphenyl)thio)methyl)trifluoroborate $4 \quad$ S6

${ }^{13} \mathrm{C}\left\{{ }^{1} \mathrm{H}\right\}$ NMR of Potassium (((3,5-dimethoxyphenyl)thio)methyl)trifluoroborate $4 \quad$ S6

${ }^{1} \mathrm{H}$ NMR of Potassium trifluoro(((4-trifluoromethyl)phenyl)thio)methyl)borate $5 \quad$ S7

${ }^{13} \mathrm{C}\left\{{ }^{1} \mathrm{H}\right\}$ NMR of Potassium trifluoro(((4-trifluoromethyl)phenyl)thio)methyl)borate $5 \quad$ S7

${ }^{1} \mathrm{H}$ NMR of Potassium trifluoro((o-tolylthio)methyl)borate $6 \quad$ S8

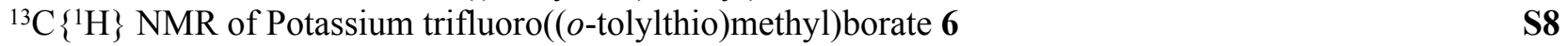

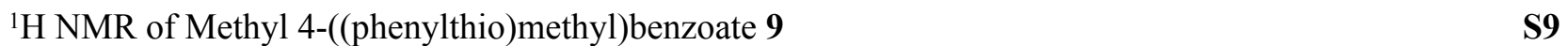

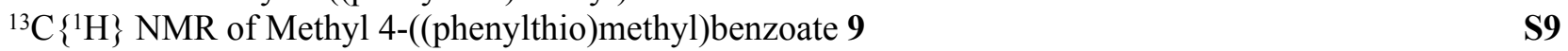

${ }^{1} \mathrm{H}$ NMR of Methyl 4-(((3,5-dimethoxyphenyl)thio)methyl)benzoate 10 $\quad$ S10

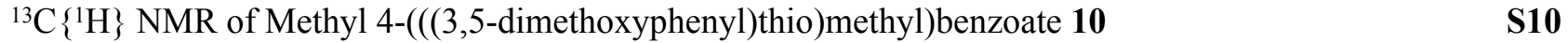

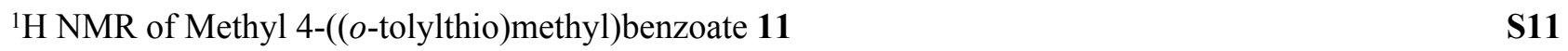

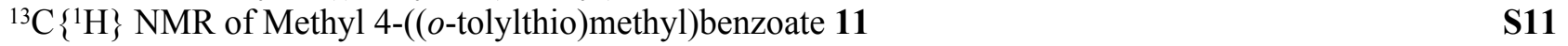

${ }^{1}$ H NMR of Methyl 4-((methylthio)methyl)benzoate 12 12

${ }^{13} \mathrm{C}\left\{{ }^{1} \mathrm{H}\right\}$ NMR of Methyl 4-((methylthio)methyl)benzoate 12

${ }^{1}$ H NMR of Methyl 4-((tert-butylthio)methyl)benzoate $13 \quad S 13$

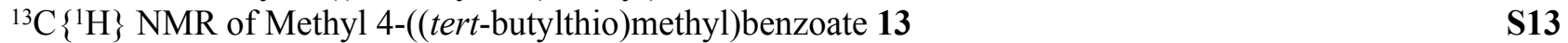

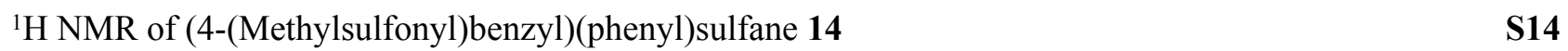

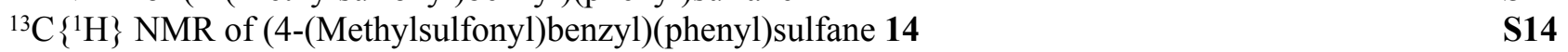

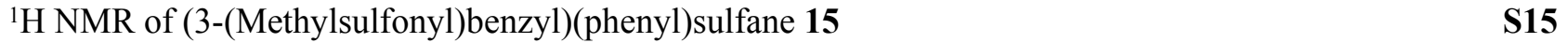

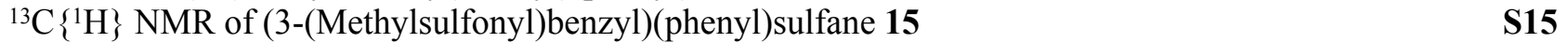

${ }^{1}$ H NMR of 1-(4-((Phenylthio)methyl)phenyl)ethan-1-one 16

${ }^{13} \mathrm{C}\left\{{ }^{1} \mathrm{H}\right\}$ NMR of 1-(4-((Phenylthio)methyl)phenyl)ethan-1-one 16

$\begin{array}{ll}{ }^{1} \mathrm{H} \text { NMR of } N, N \text {-Dimethyl-4-((phenylthio)methyl)benzamide 17 } & \text { S17 }\end{array}$

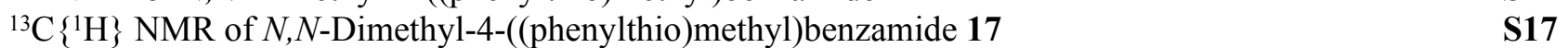

$\begin{array}{ll}{ }^{1} \mathrm{H} \text { NMR of 2-((Phenylthio)methyl)benzonitrile } 18 & \text { S18 }\end{array}$

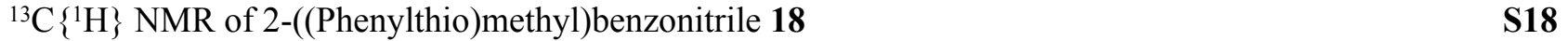

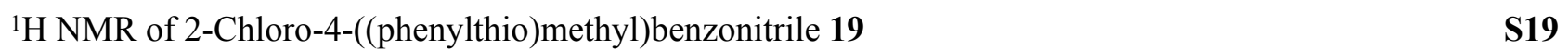

${ }^{13} \mathrm{C}\left\{{ }^{1} \mathrm{H}\right\}$ NMR of 2-Chloro-4-((phenylthio)methyl)benzonitrile 19 $\quad$ S19

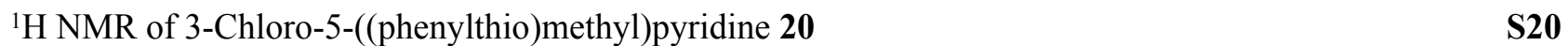

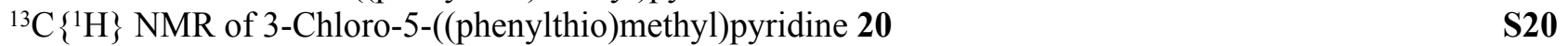

${ }^{1} \mathrm{H}$ NMR of 5-((Phenylthio)methyl)-2-(trifluoromethyl)pyridine 21 $\quad$ S21

${ }^{13} \mathrm{C}\left\{{ }^{1} \mathrm{H}\right\}$ NMR of 5-((Phenylthio)methyl)-2-(trifluoromethyl)pyridine $21 \quad$ S21

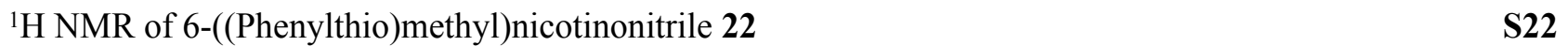

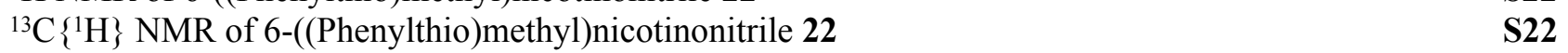

${ }^{1} \mathrm{H}$ NMR of 5-((Phenylthio)methyl)pyrimidine $\mathbf{2 3} \quad$ S23

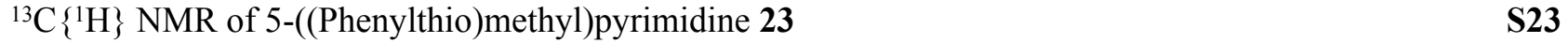




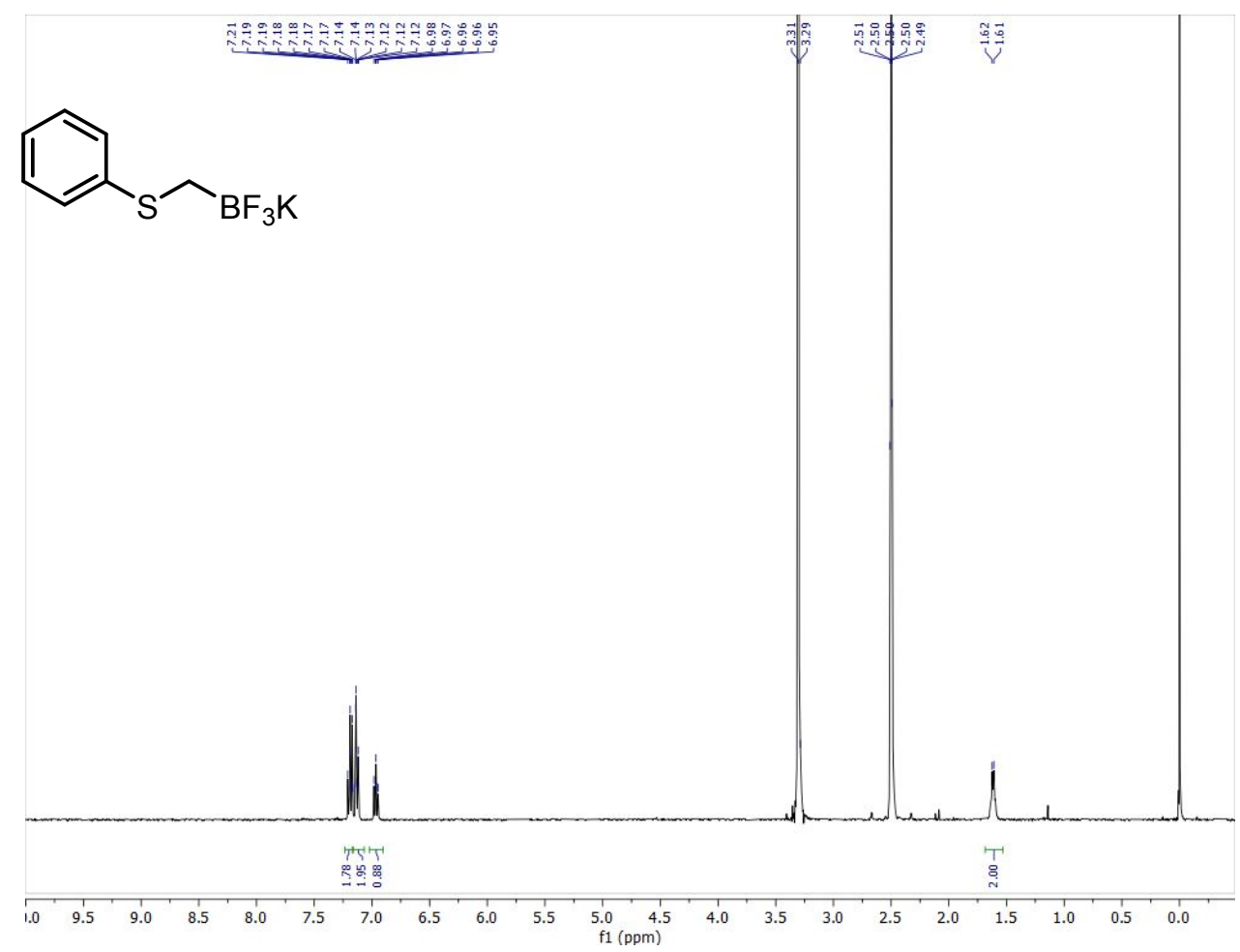

${ }^{1} \mathrm{H}$ NMR (DMSO- $d_{6}, 400 \mathrm{MHz}$ ) spectrum of potassium trifluoro((phenylthio)methyl)borate 1

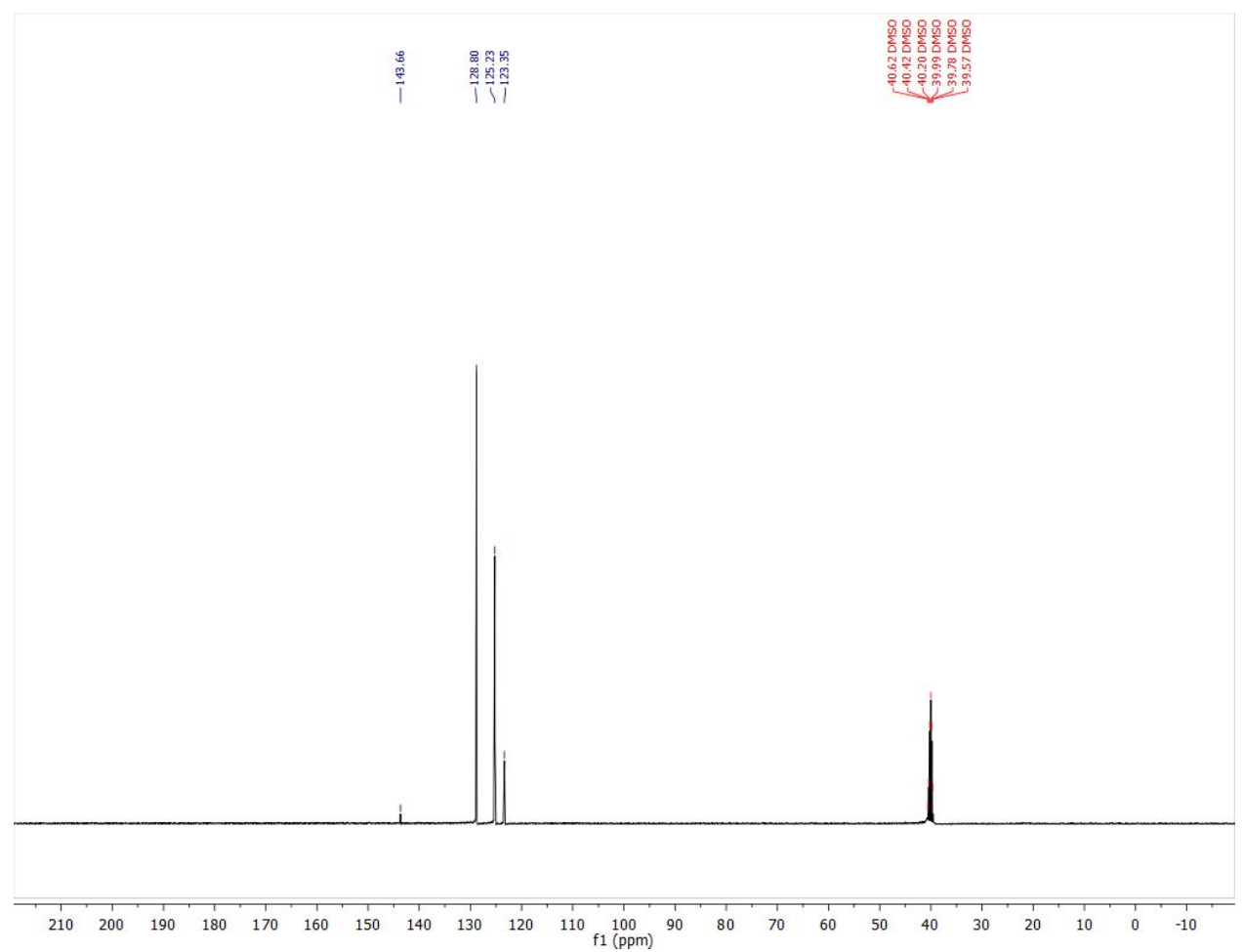

${ }^{13} \mathrm{C}\left\{{ }^{1} \mathrm{H}\right\}$ NMR (DMSO- $\left.d_{6}, 100.6 \mathrm{MHz}\right)$ spectrum of potassium trifluoro((phenylthio)methyl)borate $\mathbf{1}$ 


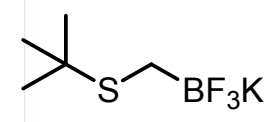

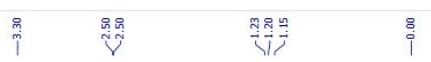

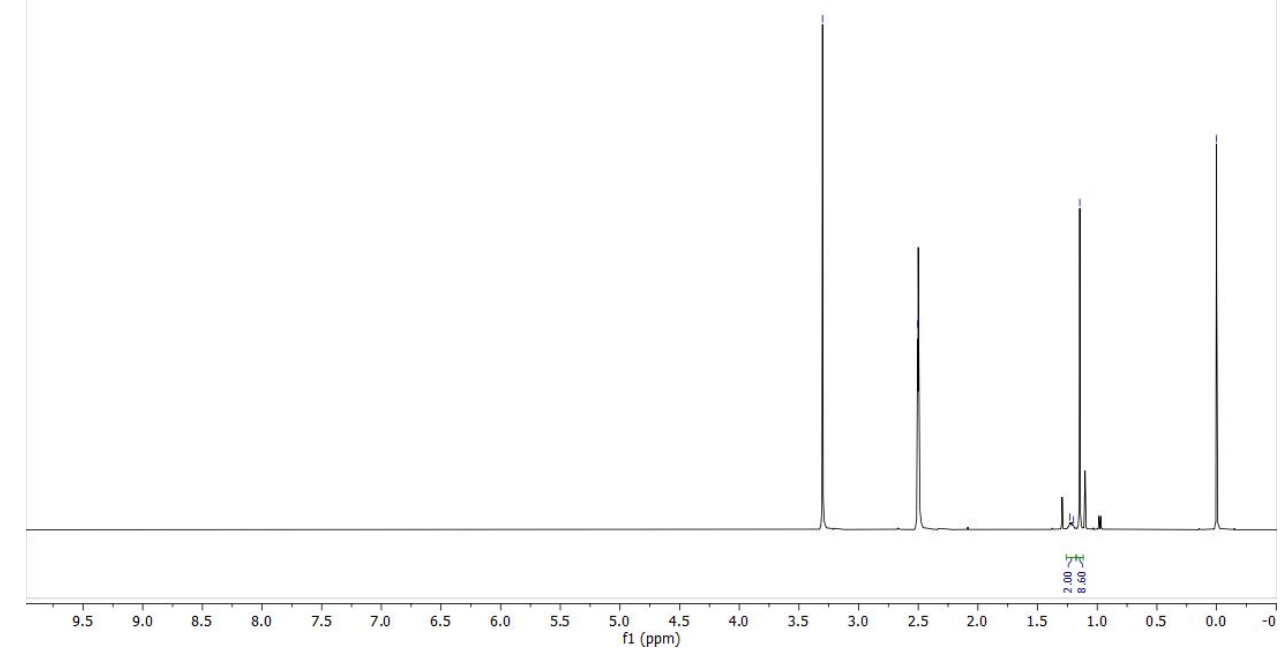

${ }^{1} \mathrm{H}$ NMR (DMSO- $d_{6}, 400 \mathrm{MHz}$ ) spectrum of potassium ((tert-butylthio)methyl)trifluoroborate 2

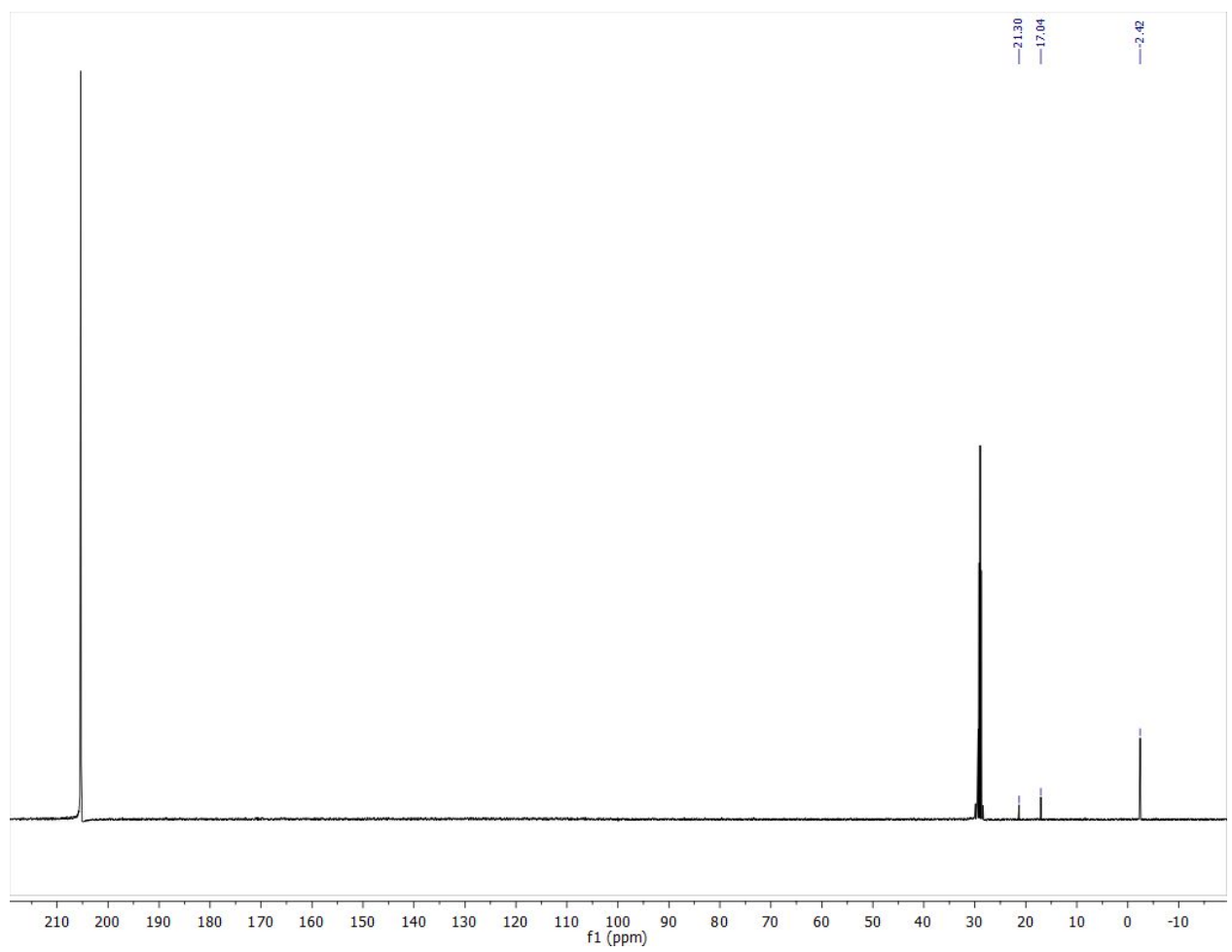

${ }^{13} \mathrm{C}\left\{{ }^{1} \mathrm{H}\right\}$ NMR (Acetone- $d_{6}, 100.6 \mathrm{MHz}$ ) spectrum of potassium ((tert-butylthio)methyl)trifluoroborate 2 


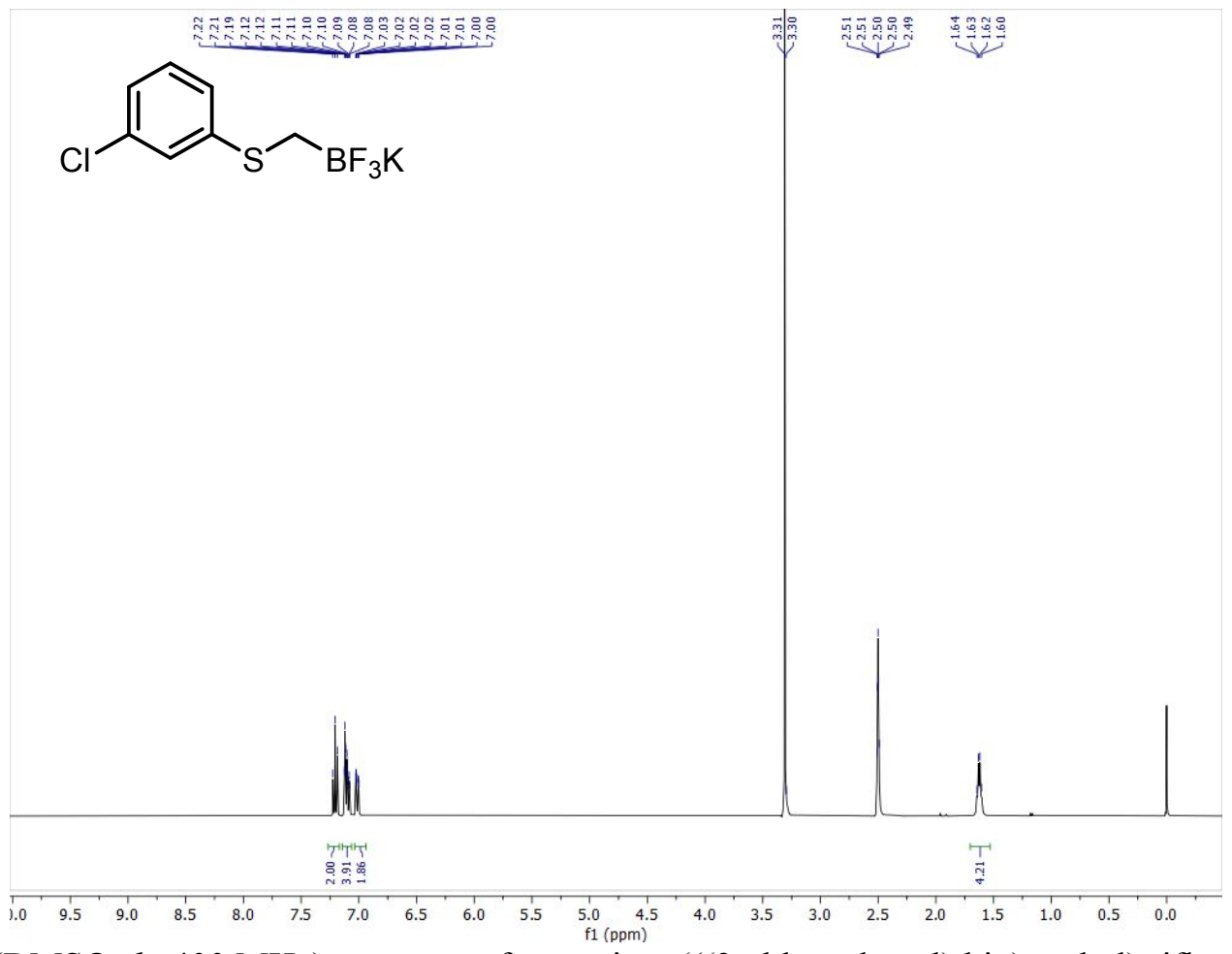

${ }^{1} \mathrm{H}$ NMR (DMSO- $\left.d_{6}, 400 \mathrm{MHz}\right)$ spectrum of potassium (((3-chlorophenyl)thio)methyl)trifluoroborate 3
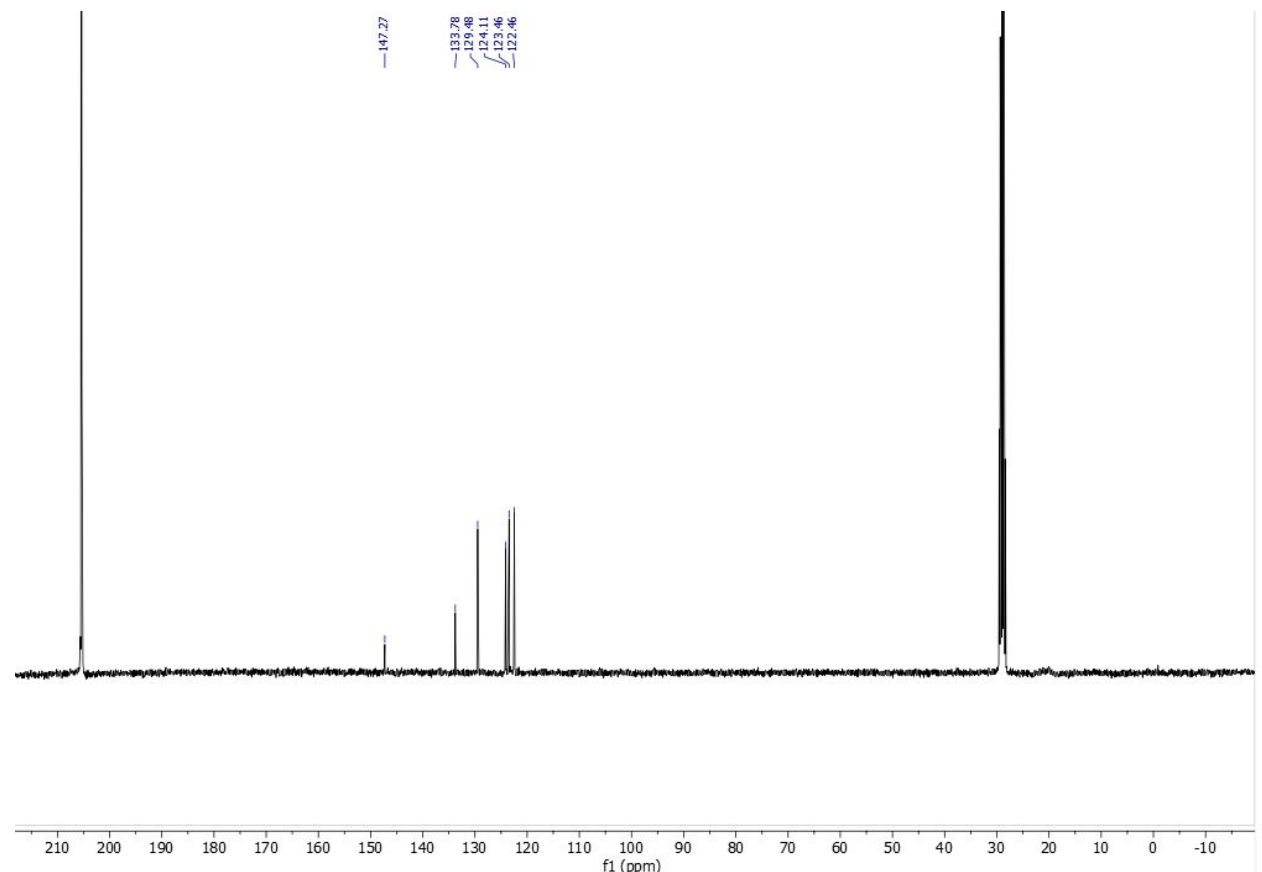

${ }^{13} \mathrm{C}\left\{{ }^{1} \mathrm{H}\right\}$ NMR (Acetone- $\left.d_{6}, 100.6 \mathrm{MHz}\right)$ spectrum of potassium (((3-chlorophenyl)thio)methyl)trifluoroborate 3 


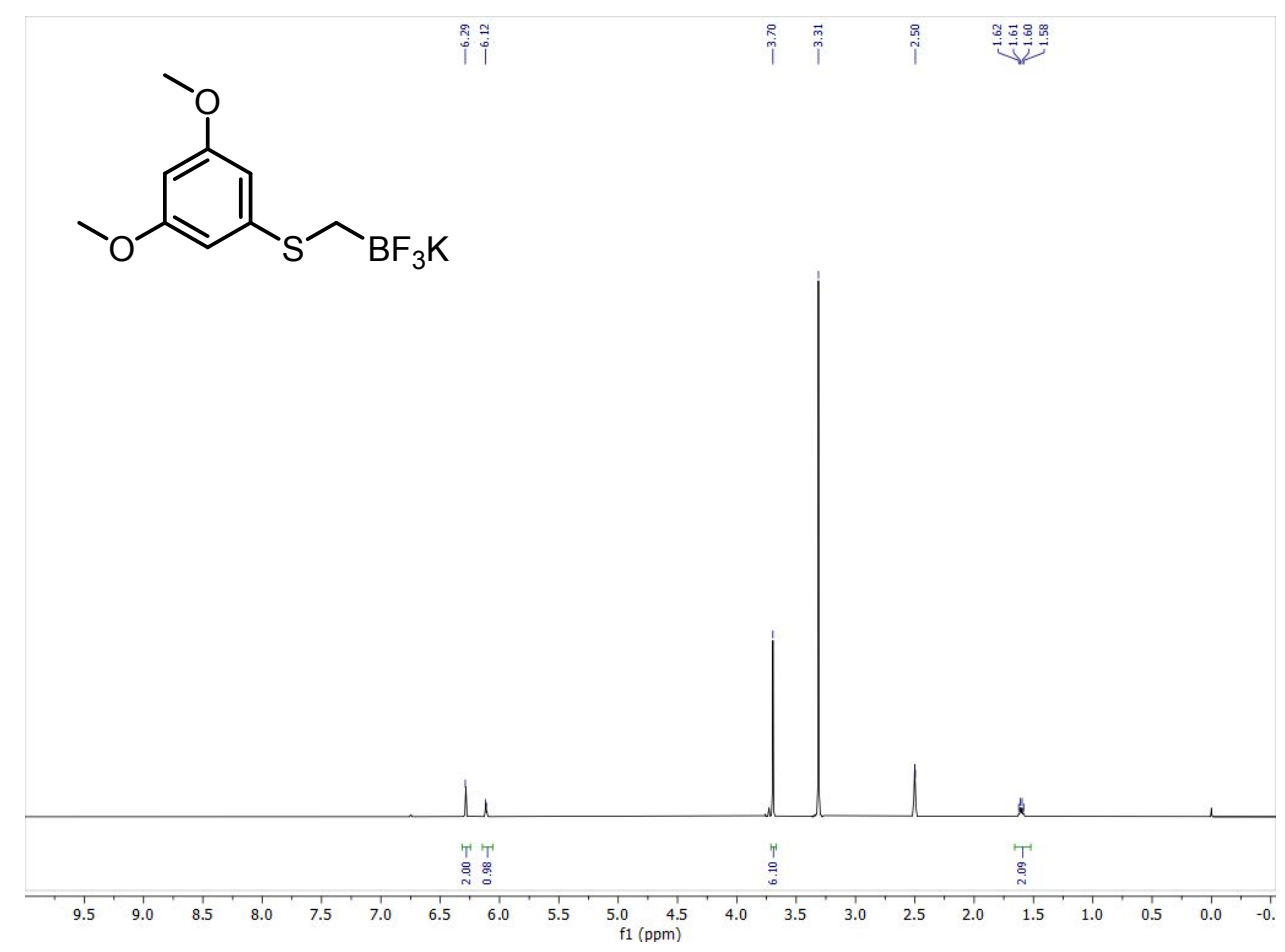

${ }^{1} \mathrm{H}$ NMR (DMSO- $\left.d_{6}, 400 \mathrm{MHz}\right)$ spectrum of potassium (((3,5-dimethoxyphenyl)thio)methyl)trifluoroborate 4
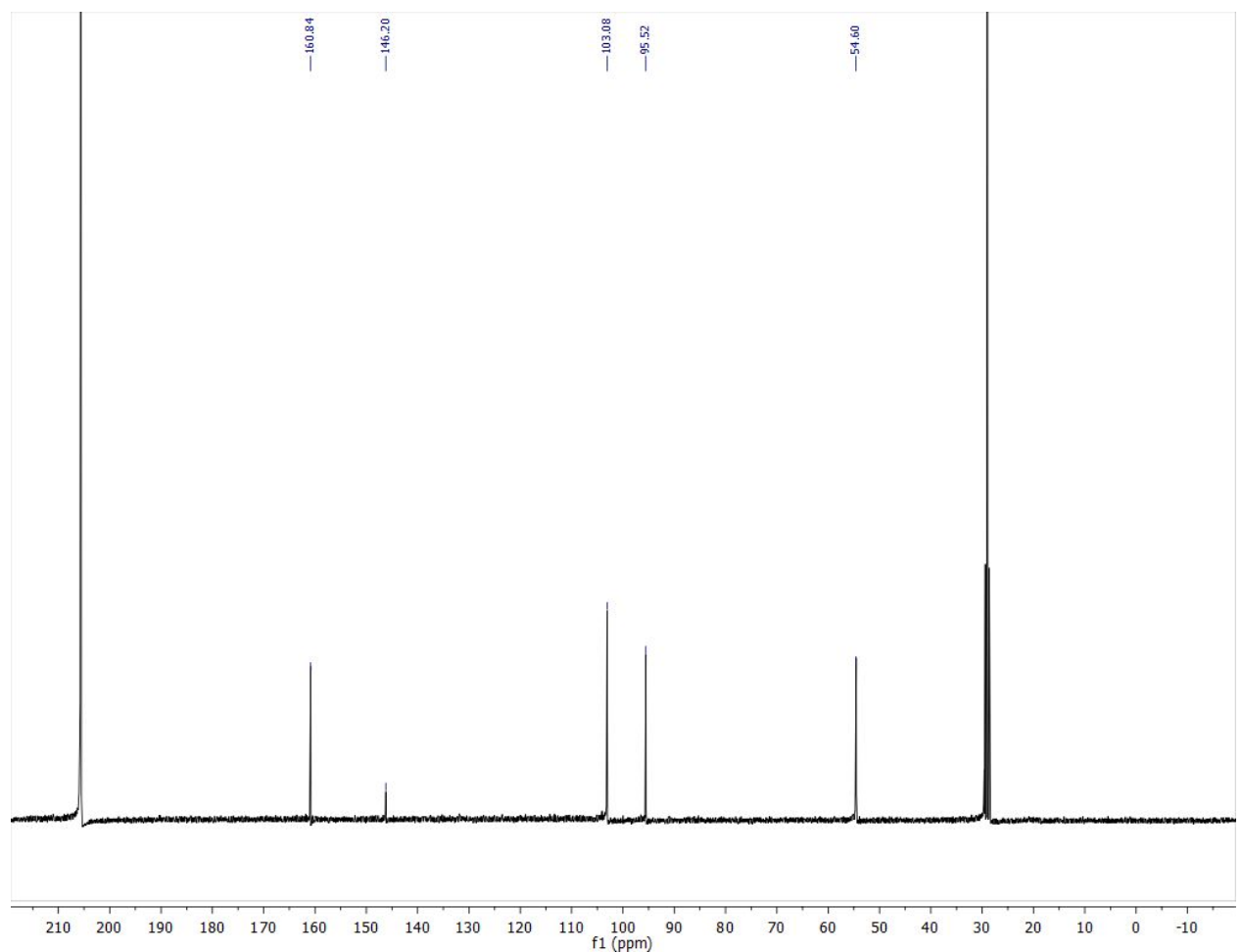

${ }^{13} \mathrm{C}\left\{{ }^{1} \mathrm{H}\right\}$ NMR (Acetone- $\left.d_{6}, 100.6 \mathrm{MHz}\right)$ spectrum of potassium $(((3,5-$ dimethoxyphenyl)thio)methyl)trifluoroborate 4 


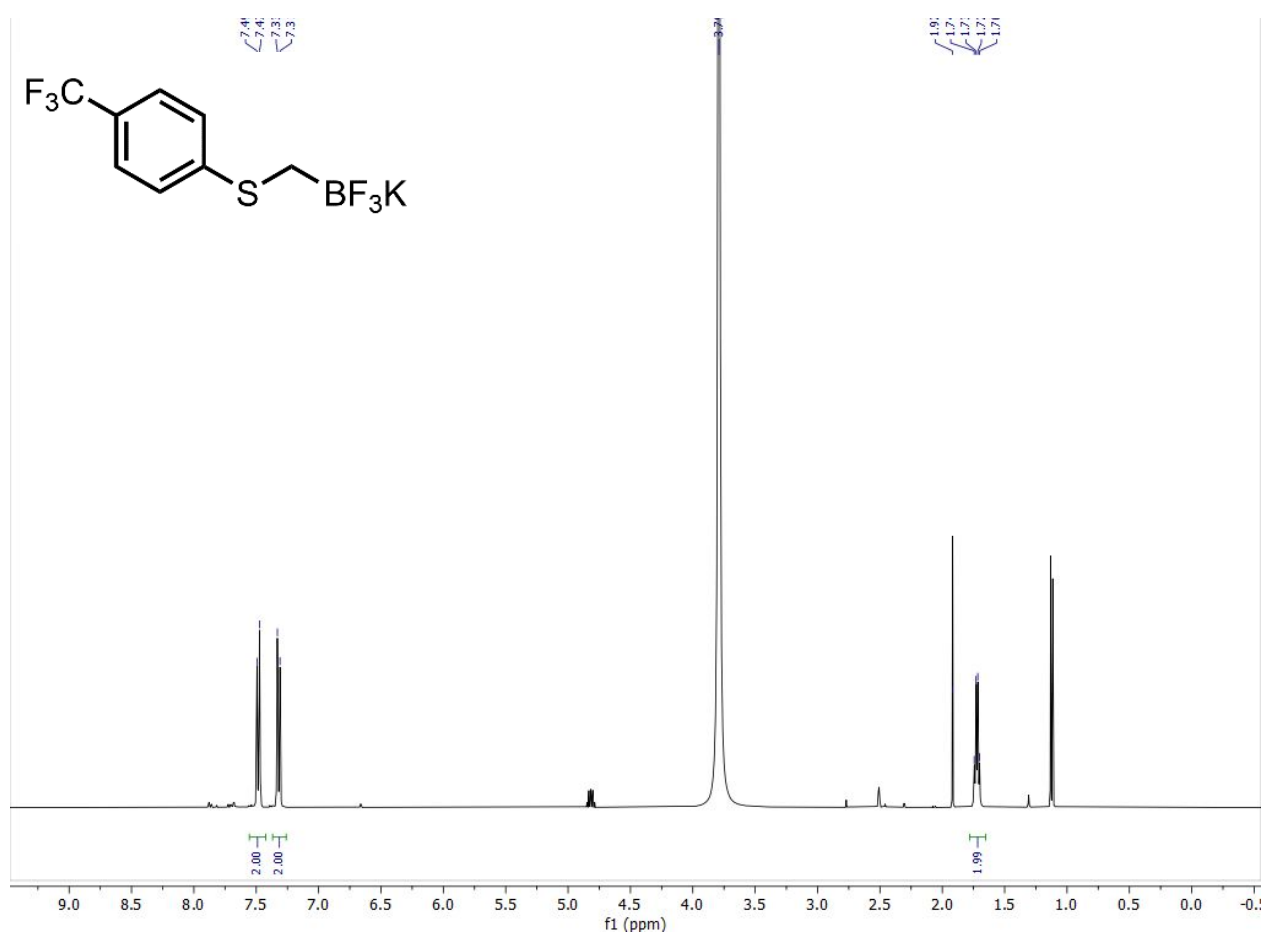

${ }^{1} \mathrm{H}$ NMR (DMSO- $\left.d_{6}, 400 \mathrm{MHz}\right)$ spectrum of potassium trifluoro(((4-trifluoromethyl)phenyl)thio)methyl)borate 5
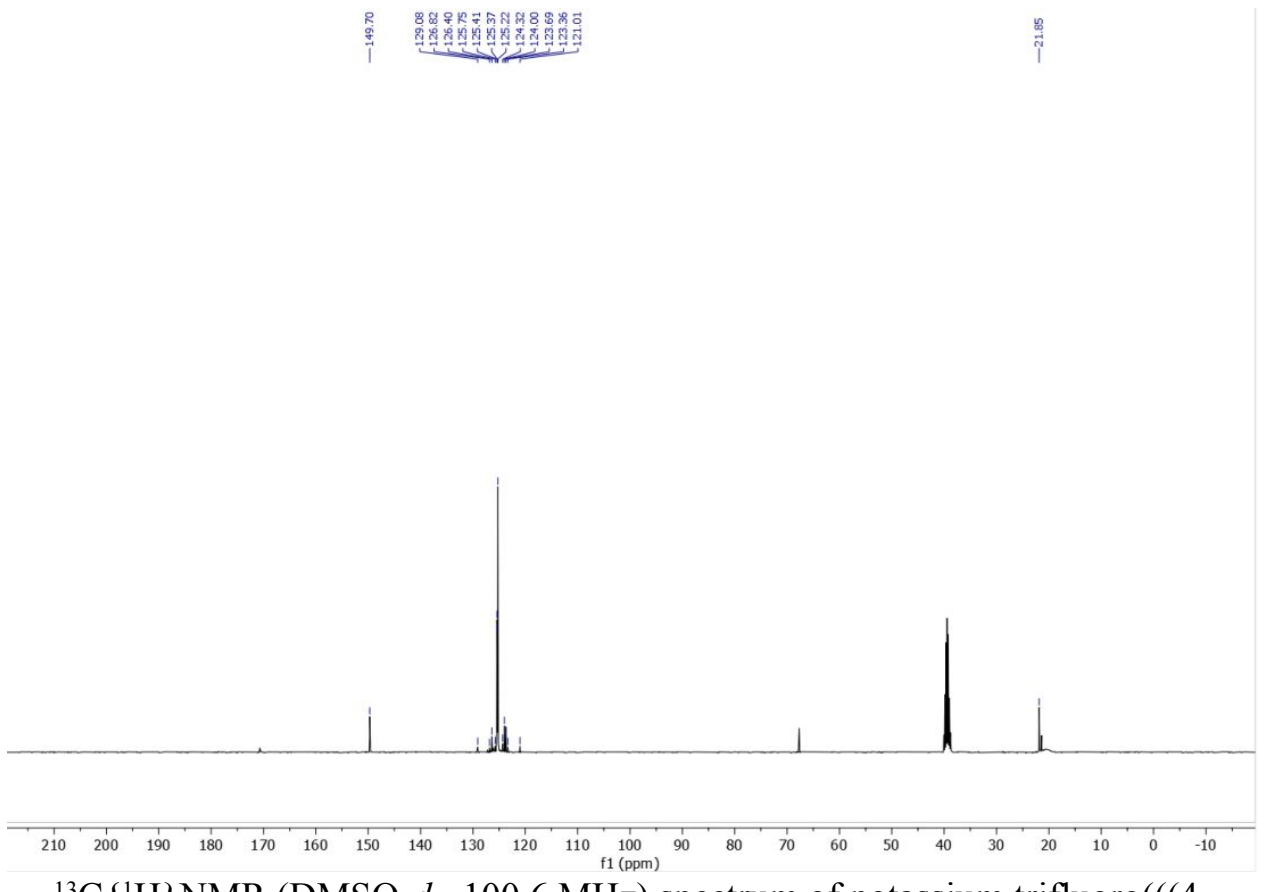

${ }^{13} \mathrm{C}\left\{{ }^{1} \mathrm{H}\right\} \mathrm{NMR}$ (DMSO- $\left.d_{6}, 100.6 \mathrm{MHz}\right)$ spectrum of potassium trifluoro(((4trifluoromethyl)phenyl)thio)methyl)borate 5 


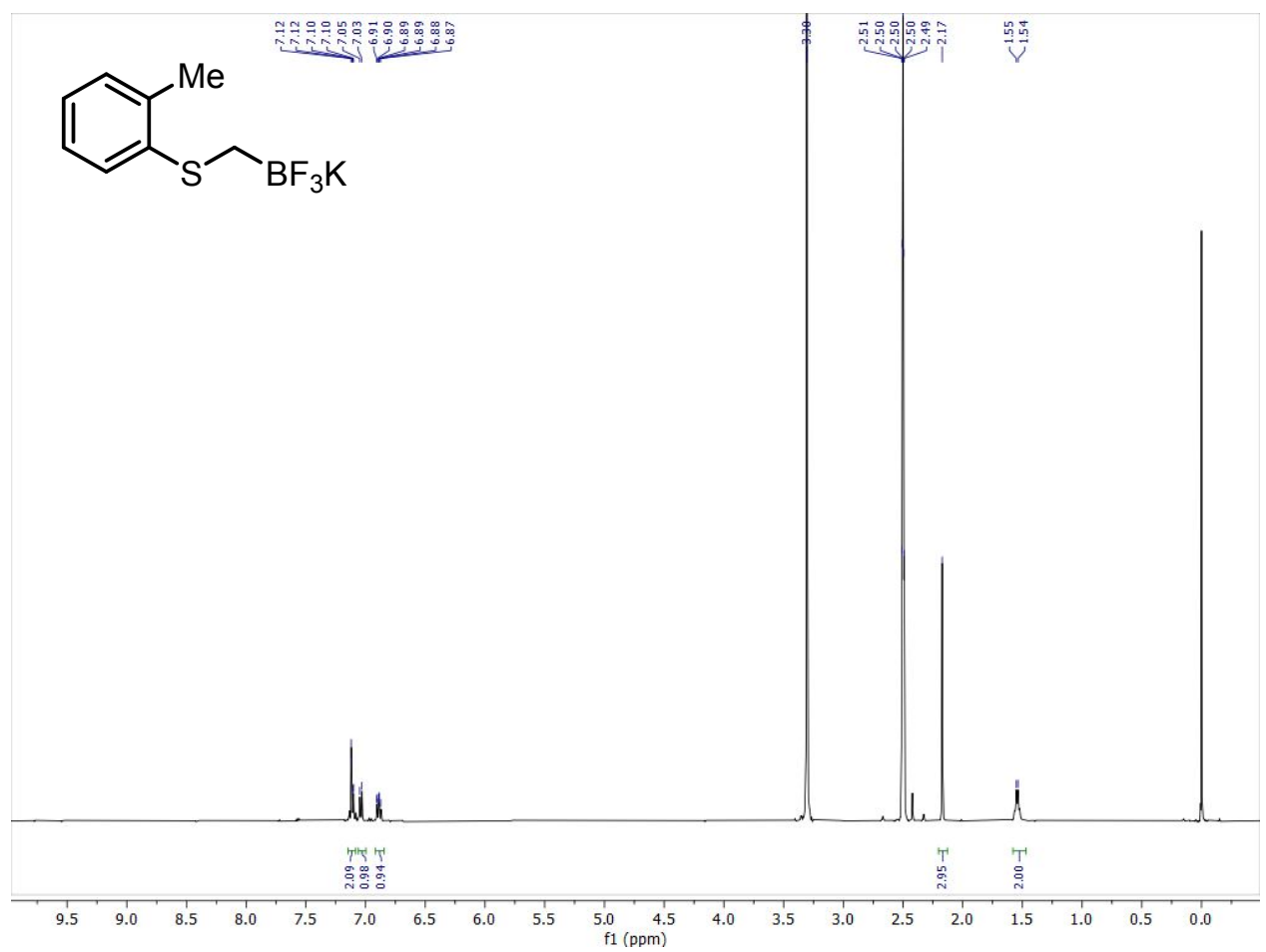

${ }^{1} \mathrm{H}$ NMR (DMSO- $\left.d_{6}, 400 \mathrm{MHz}\right)$ spectrum of potassium trifluoro((o-tolylthio)methyl)borate 6

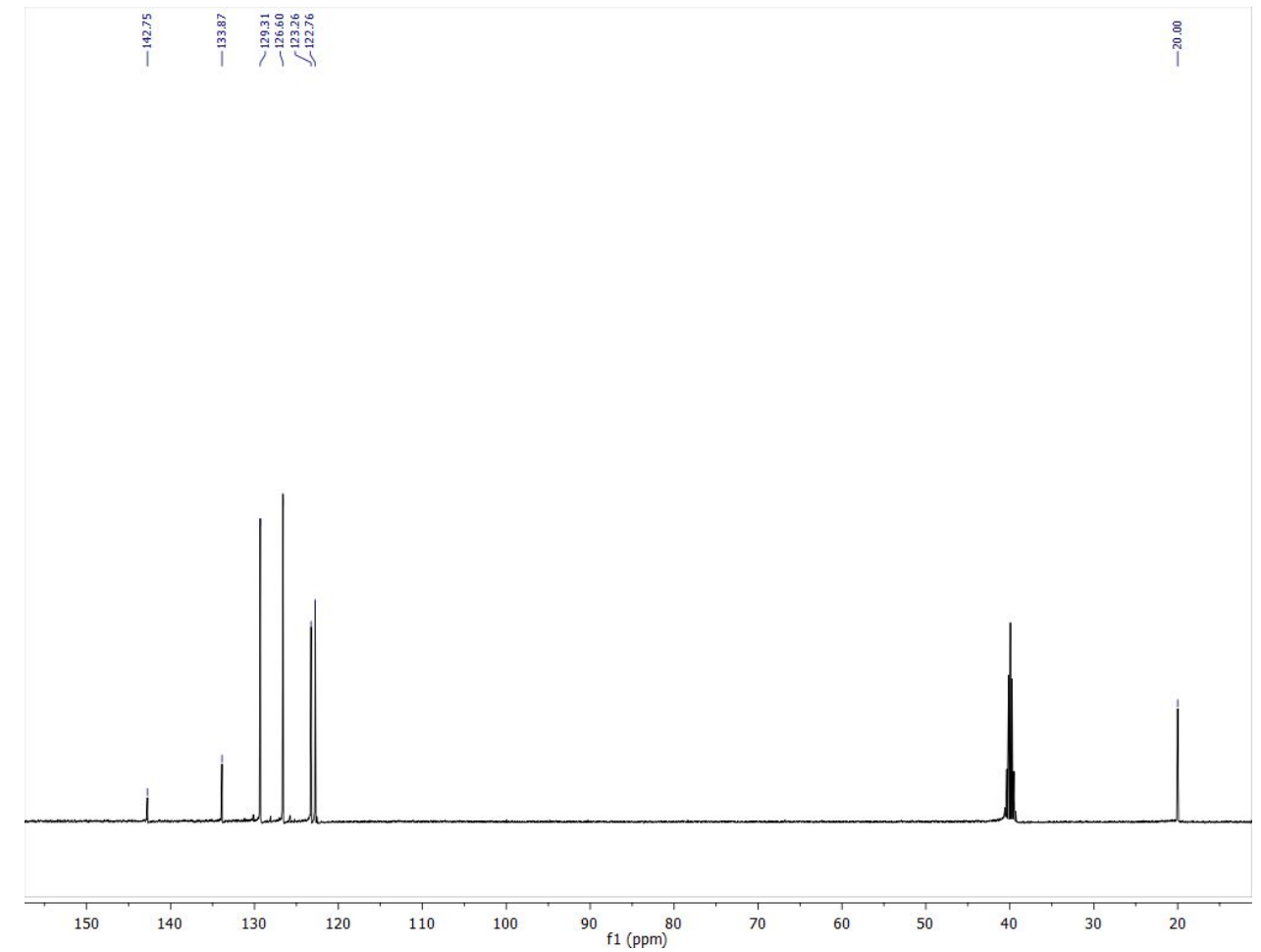

${ }^{13} \mathrm{C}\left\{{ }^{1} \mathrm{H}\right\}$ NMR (DMSO- $\left.d_{6}, 100.6 \mathrm{MHz}\right)$ spectrum of potassium trifluoro((o-tolylthio)methyl)borate 6 


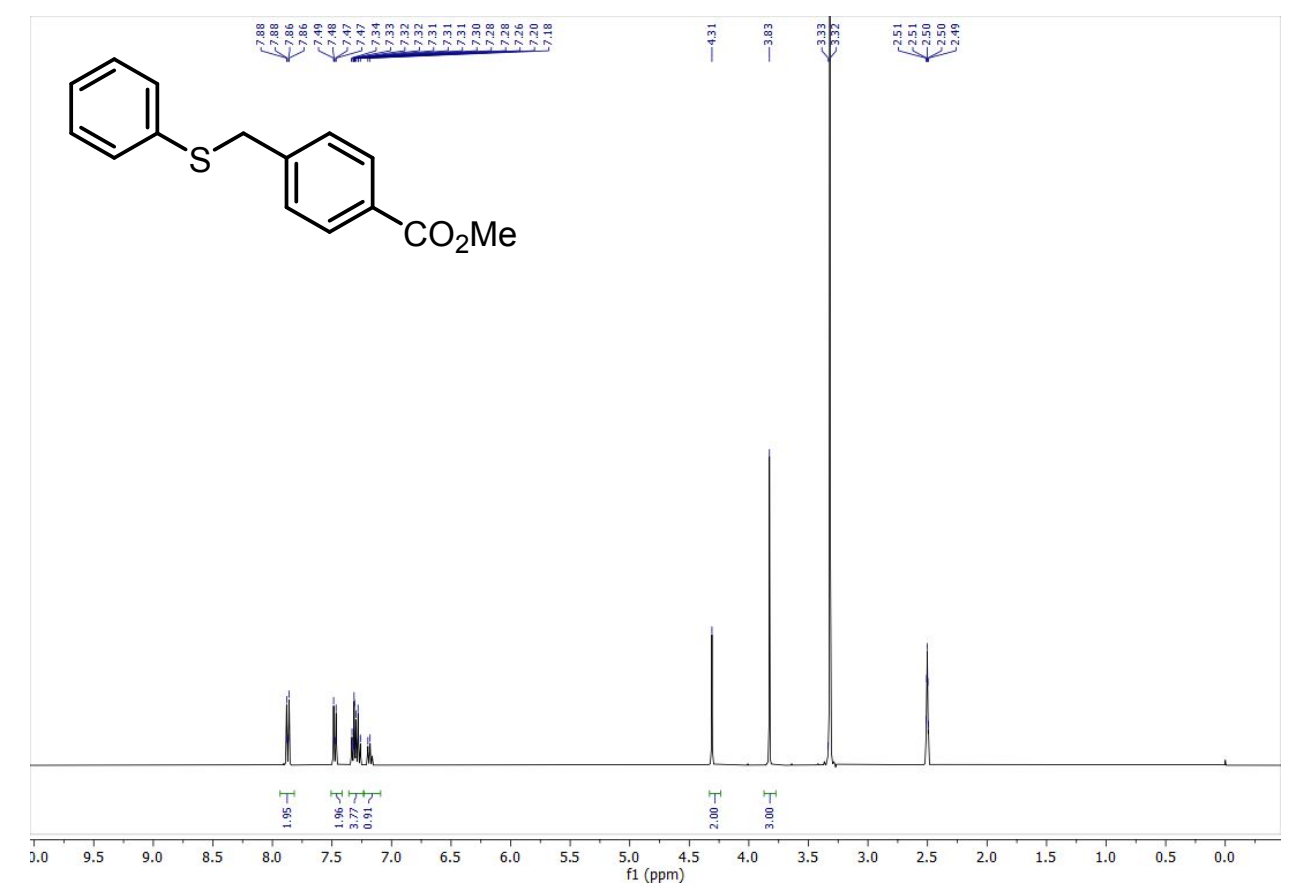

${ }^{1} \mathrm{H}$ NMR (DMSO- $\left.d_{6}, 400 \mathrm{MHz}\right)$ spectrum of methyl 4-((phenylthio)methyl)benzoate 9

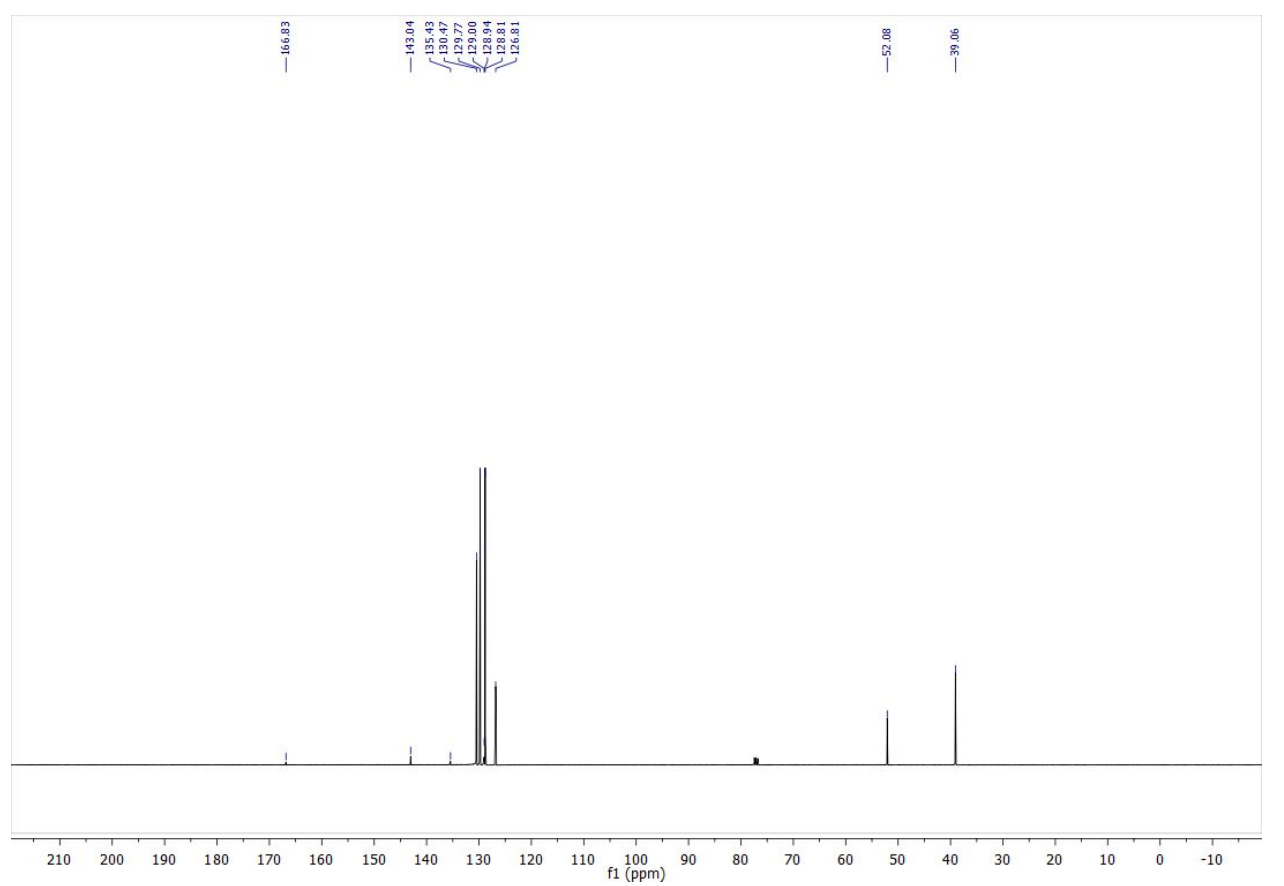

${ }^{13} \mathrm{C}\left\{{ }^{1} \mathrm{H}\right\} \mathrm{NMR}\left(\mathrm{CDCl}_{3}, 100.6 \mathrm{MHz}\right)$ spectrum of methyl 4-((phenylthio)methyl)benzoate 9 


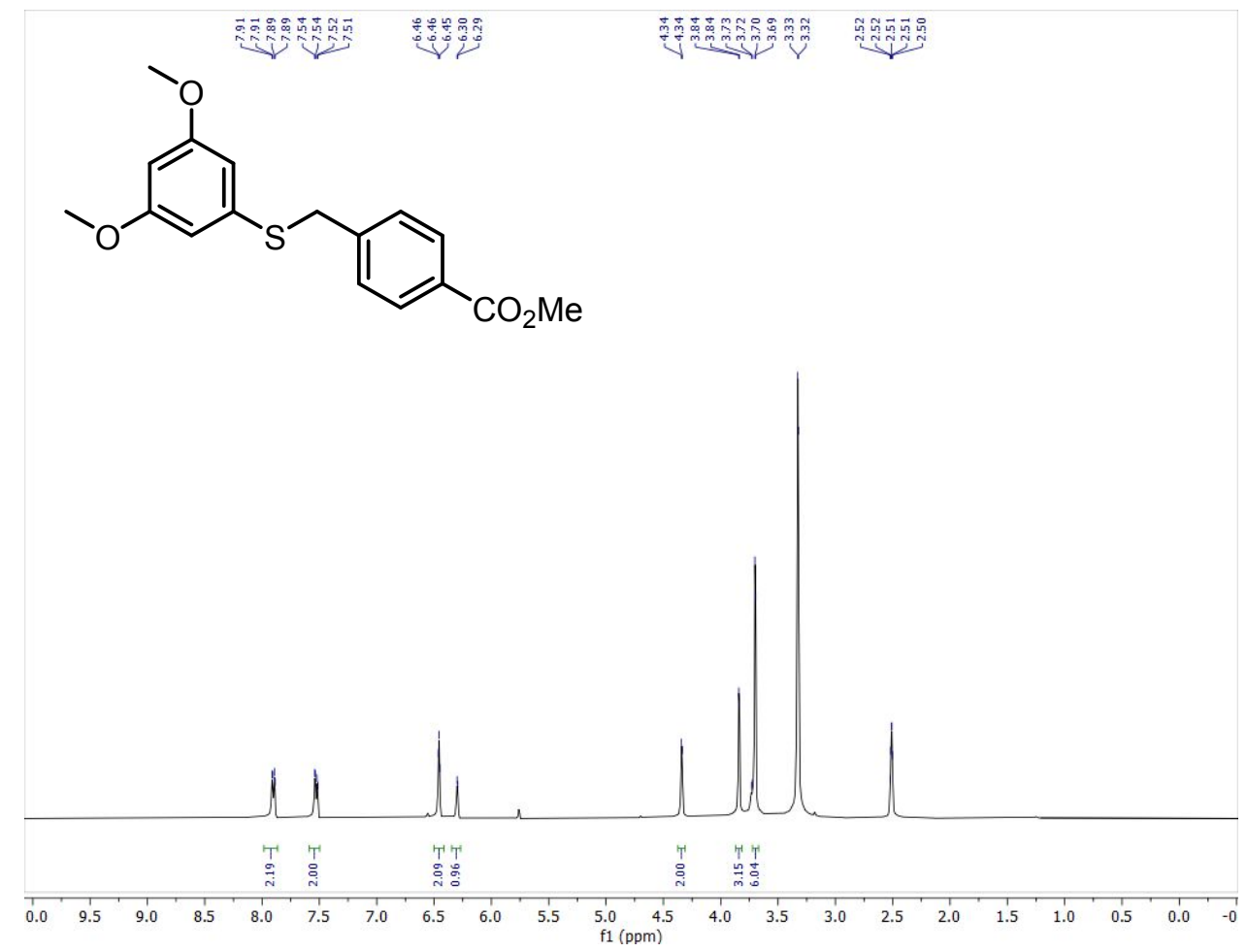

${ }^{1} \mathrm{H}$ NMR (DMSO- $\left.d_{6}, 400 \mathrm{MHz}\right)$ spectrum of methyl 4-(((3,5-dimethoxyphenyl)thio)methyl)benzoate $\mathbf{1 0}$

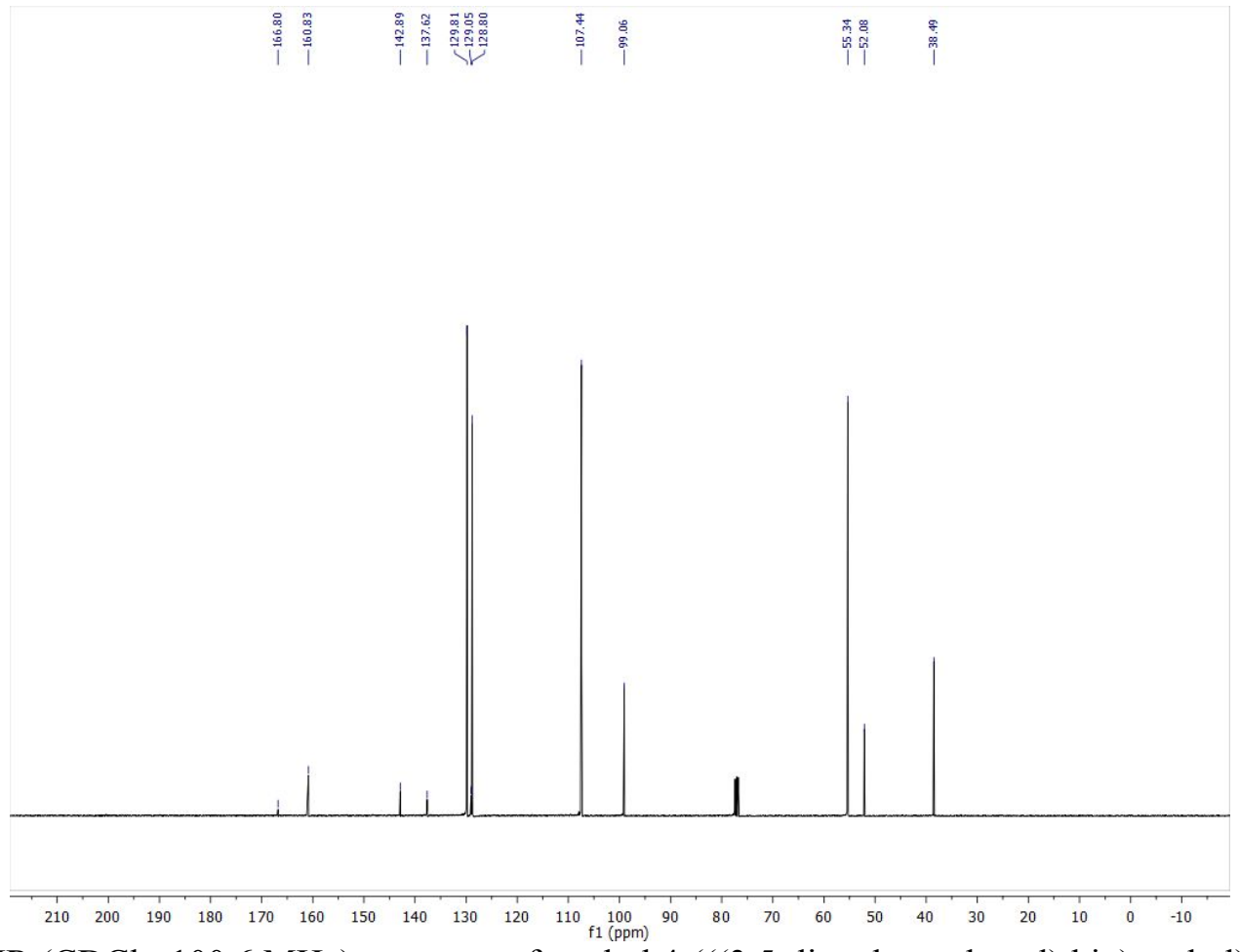

${ }^{13} \mathrm{C}\left\{{ }^{1} \mathrm{H}\right\}$ NMR $\left(\mathrm{CDCl}_{3}, 100.6 \mathrm{MHz}\right)$ spectrum of methyl 4-(((3,5-dimethoxyphenyl)thio)methyl)benzoate $\mathbf{1 0}$ 


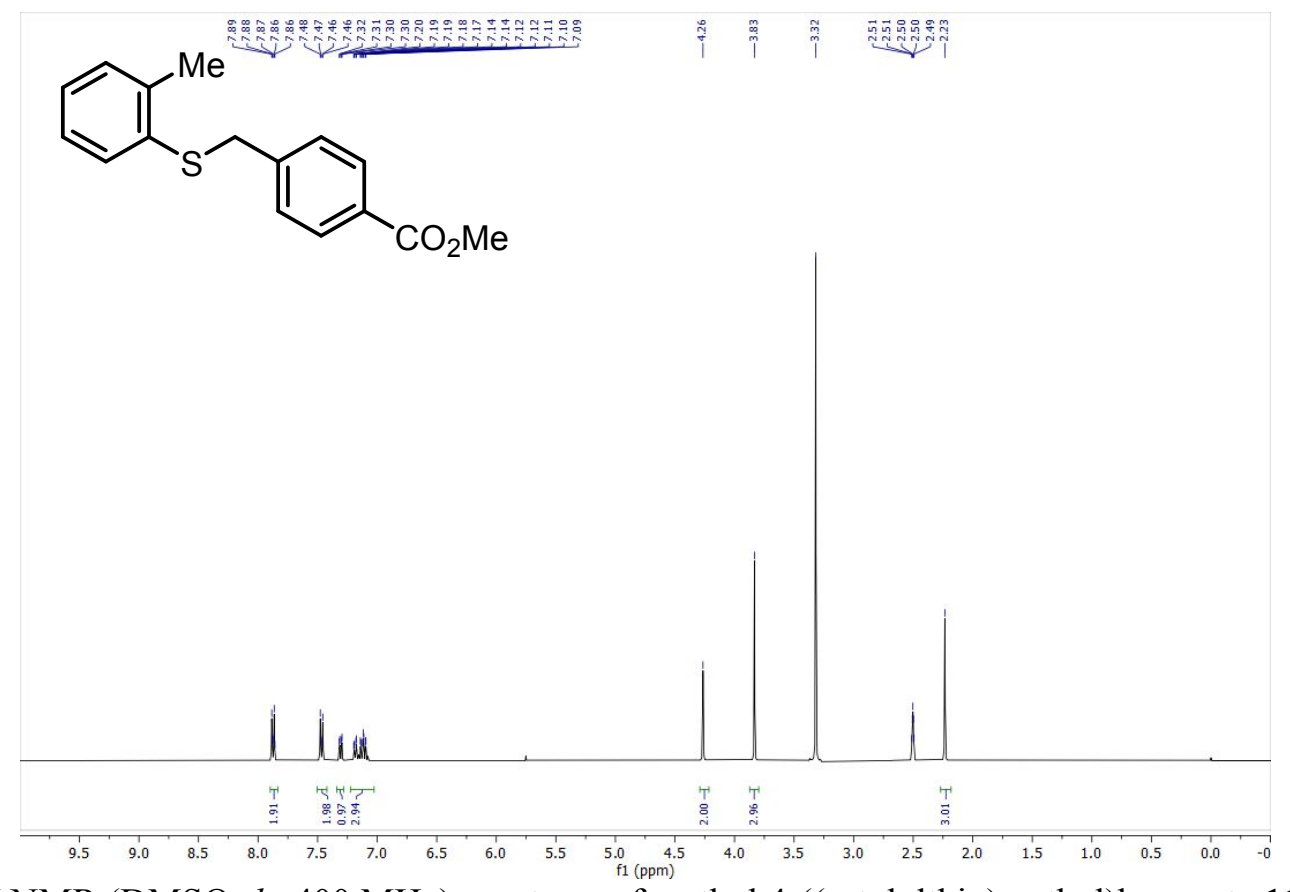

${ }^{1} \mathrm{H}$ NMR (DMSO- $\left.d_{6}, 400 \mathrm{MHz}\right)$ spectrum of methyl 4-((o-tolylthio)methyl)benzoate 11

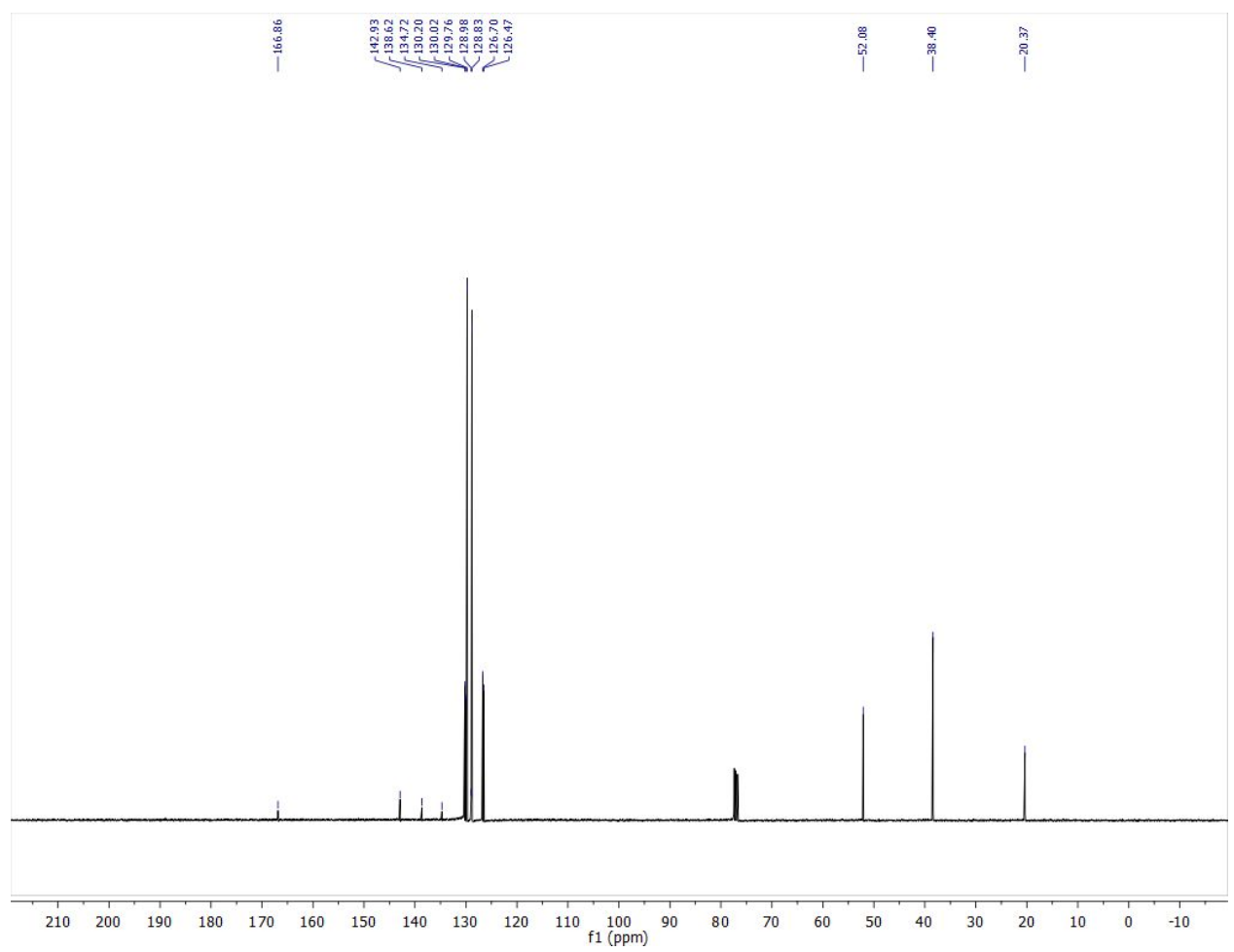

${ }^{13} \mathrm{C}\left\{{ }^{1} \mathrm{H}\right\}$ NMR $\left(\mathrm{CDCl}_{3}, 100.6 \mathrm{MHz}\right)$ spectrum of methyl 4-((o-tolylthio)methyl)benzoate 11 


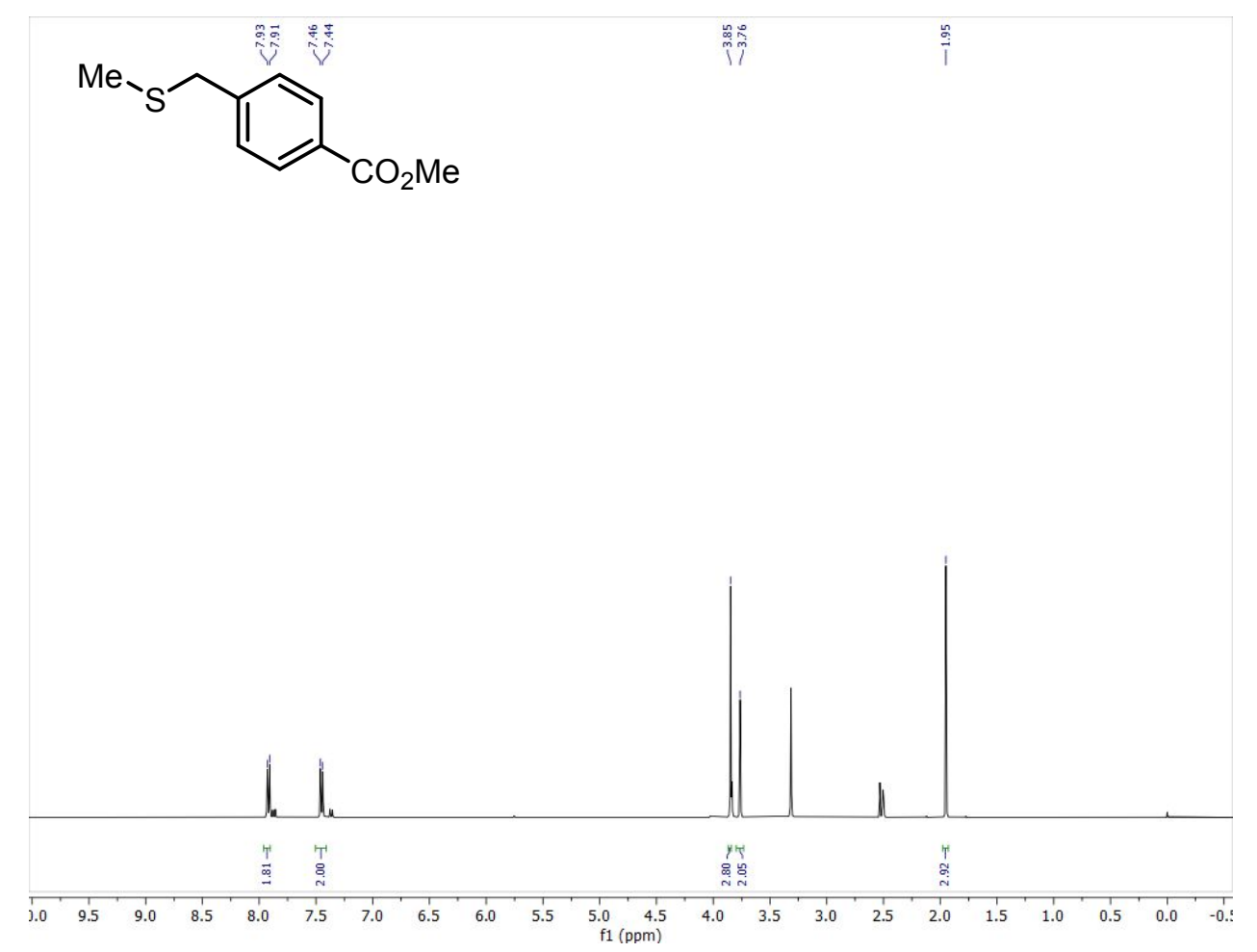

${ }^{1} \mathrm{H}$ NMR (DMSO- $\left.d_{6}, 400 \mathrm{MHz}\right)$ spectrum of methyl 4-((methylthio)methyl)benzoate 12

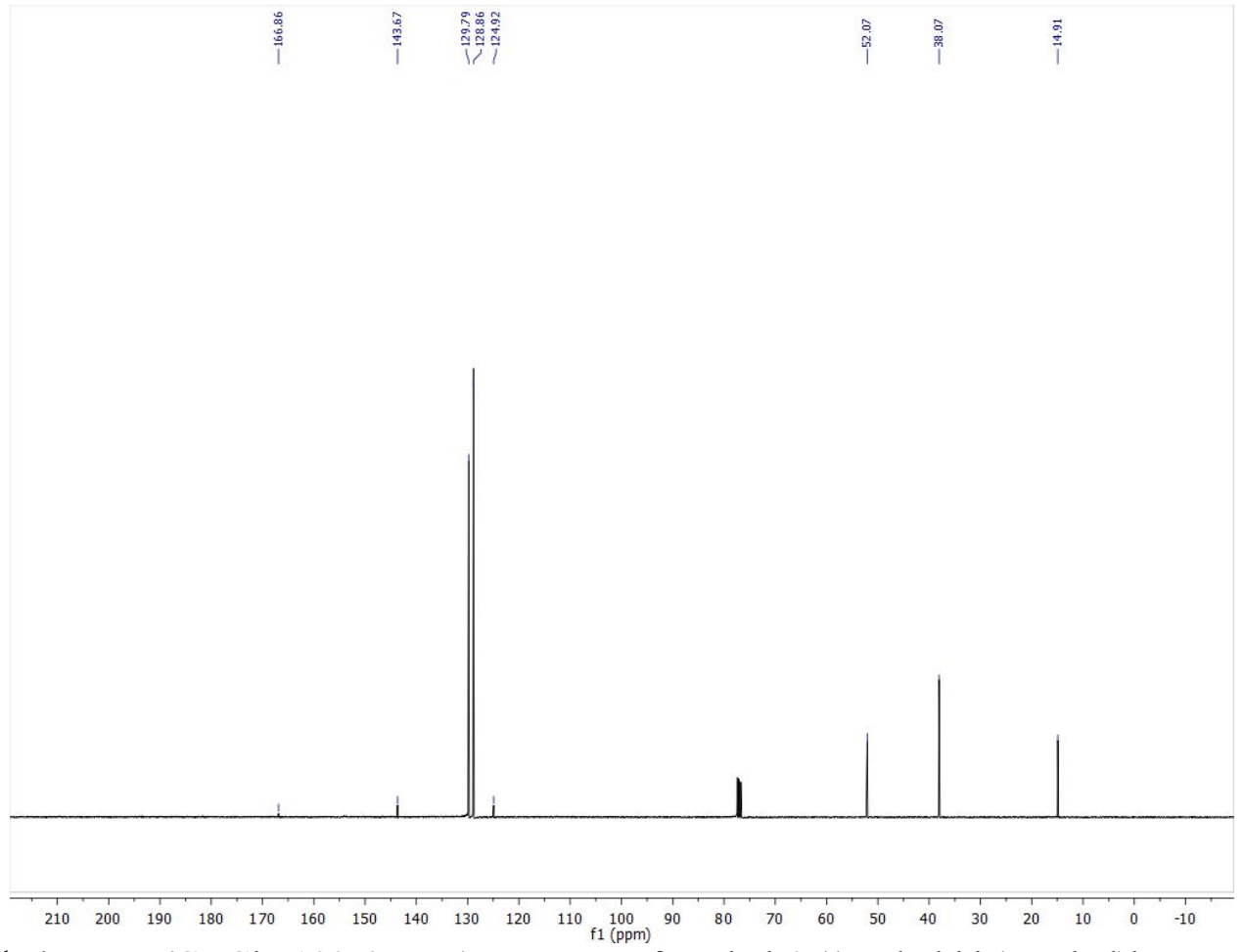

${ }^{13} \mathrm{C}\left\{{ }^{1} \mathrm{H}\right\}$ NMR $\left(\mathrm{CDCl}_{3}, 100.6 \mathrm{MHz}\right)$ spectrum of methyl 4-((methylthio)methyl)benzoate 12 


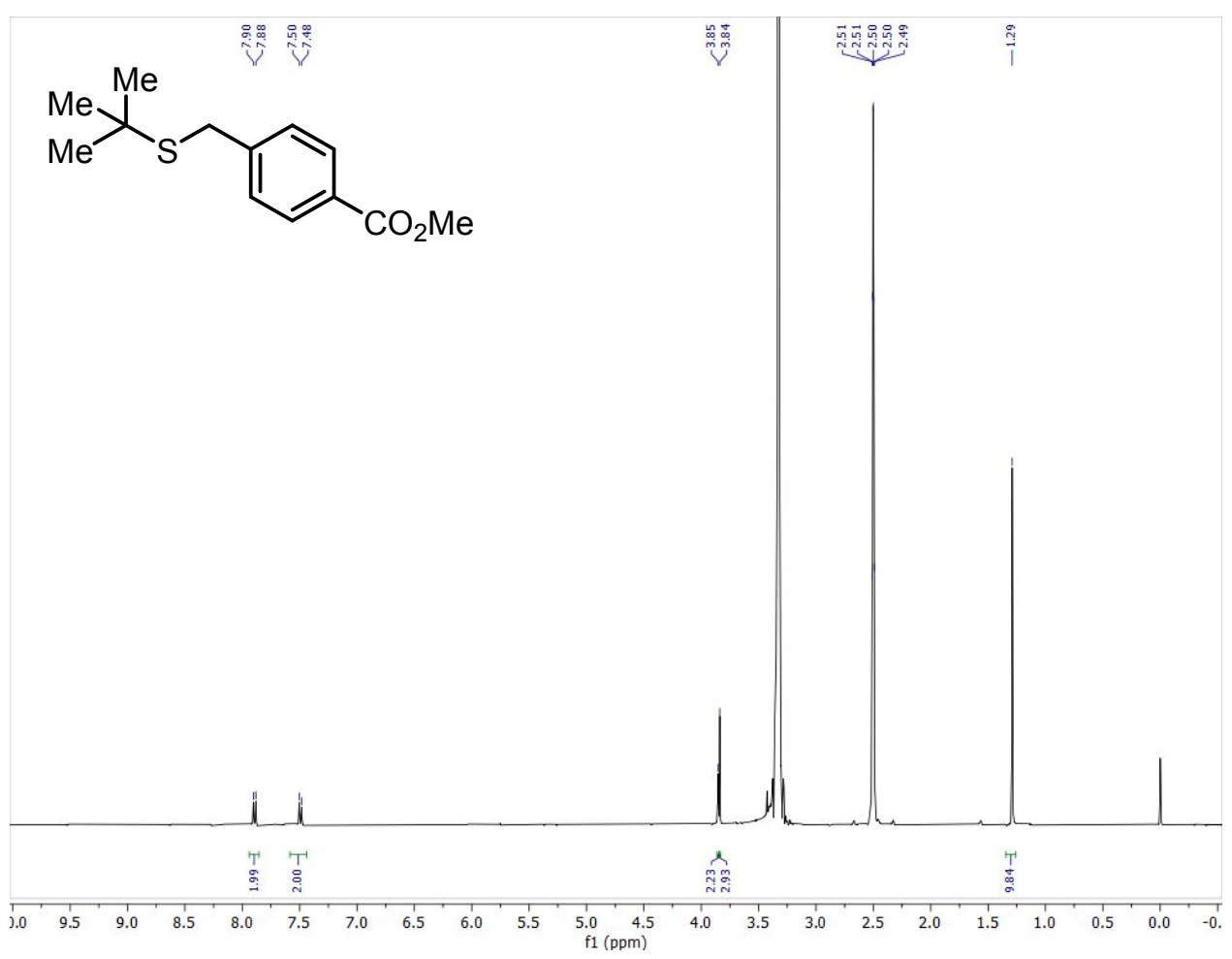

${ }^{1} \mathrm{H}$ NMR (DMSO- $\left.d_{6}, 400 \mathrm{MHz}\right)$ spectrum of methyl 4-((tert-butylthio)methyl)benzoate 13

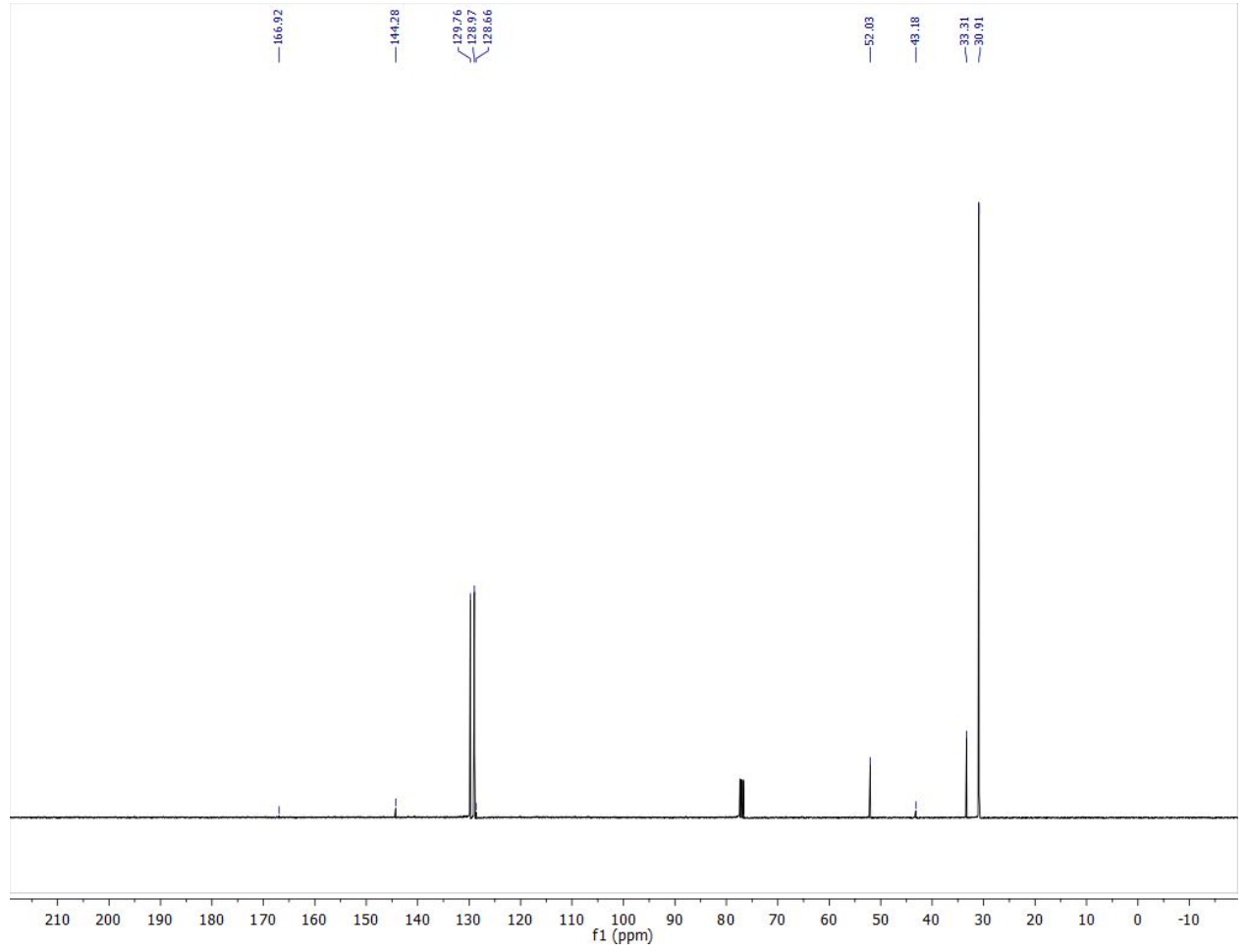

${ }^{13} \mathrm{C}\left\{{ }^{1} \mathrm{H}\right\}$ NMR $\left(\mathrm{CDCl}_{3}, 100.6 \mathrm{MHz}\right)$ spectrum of methyl 4-((tert-butylthio)methyl)benzoate $\mathbf{1 3}$ 


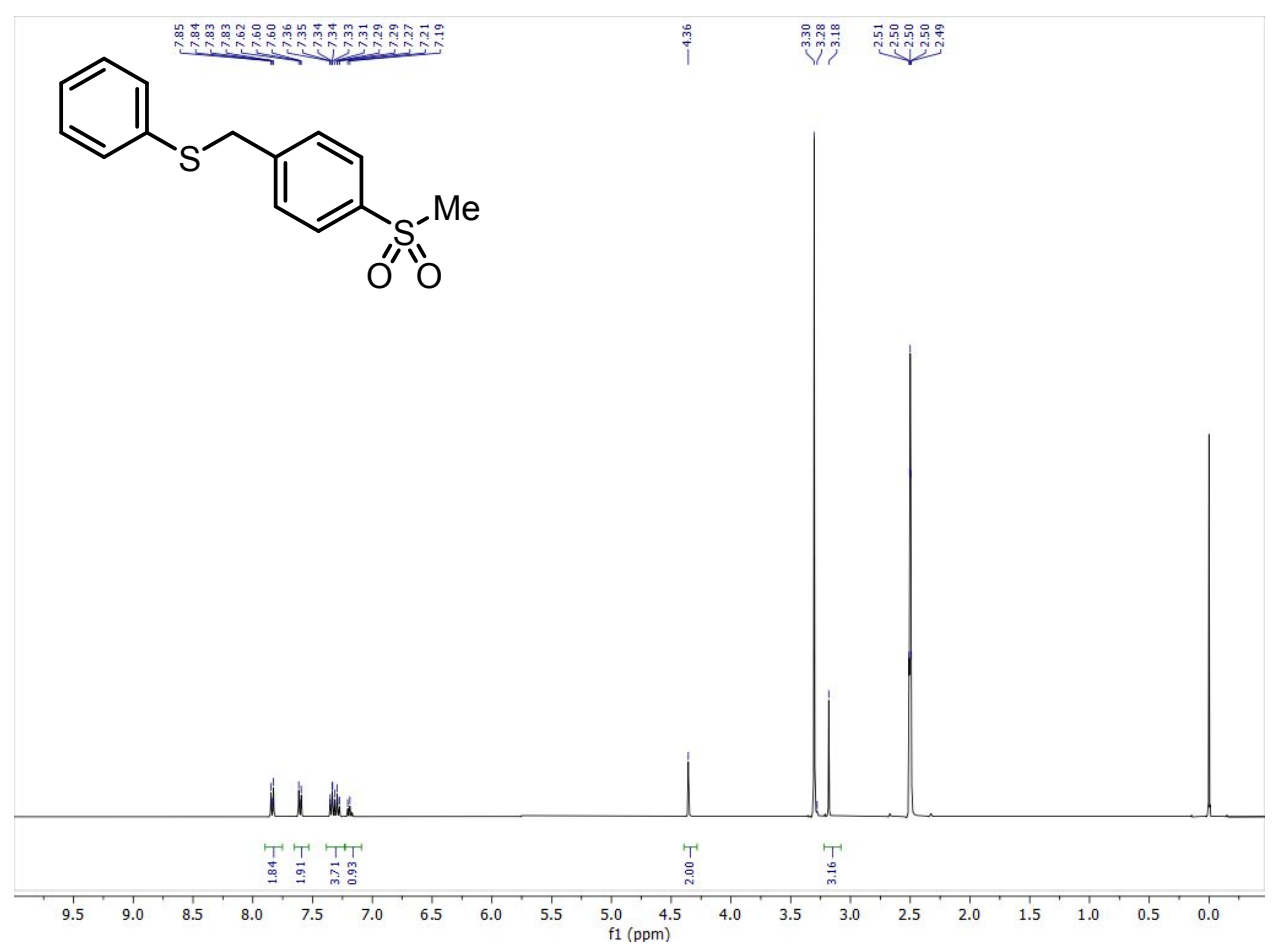

${ }^{1} \mathrm{H}$ NMR (DMSO- $d_{6}, 400 \mathrm{MHz}$ ) spectrum of (4-(methylsulfonyl)benzyl)(phenyl)sulfane 14

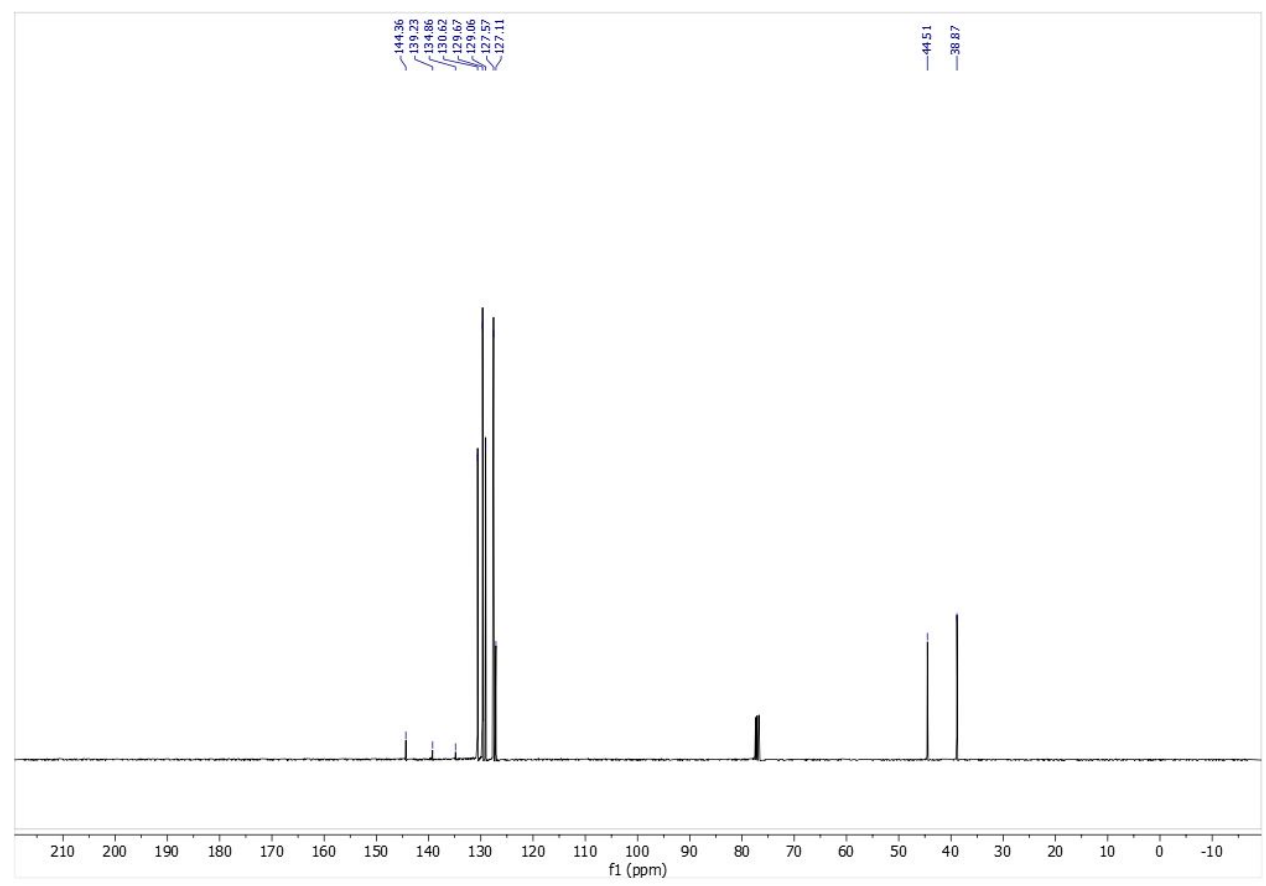

${ }^{13} \mathrm{C}\left\{{ }^{1} \mathrm{H}\right\}$ NMR $\left(\mathrm{CDCl}_{3}, 100.6 \mathrm{MHz}\right)$ spectrum of (4-(methylsulfonyl)benzyl)(phenyl)sulfane 14 


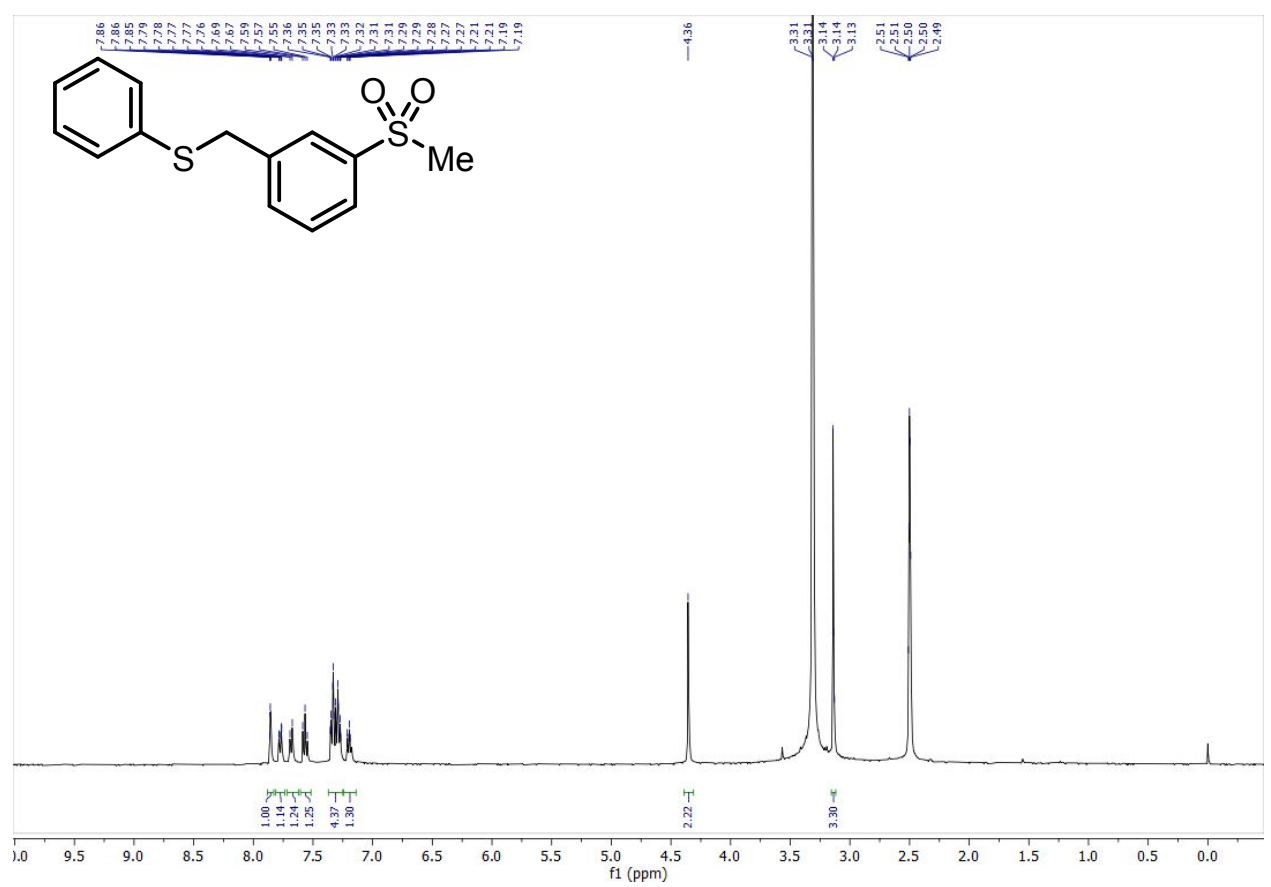

${ }^{1} \mathrm{H}$ NMR (DMSO- $d_{6}, 400 \mathrm{MHz}$ ) spectrum of (3-(methylsulfonyl)benzyl)(phenyl)sulfane 15

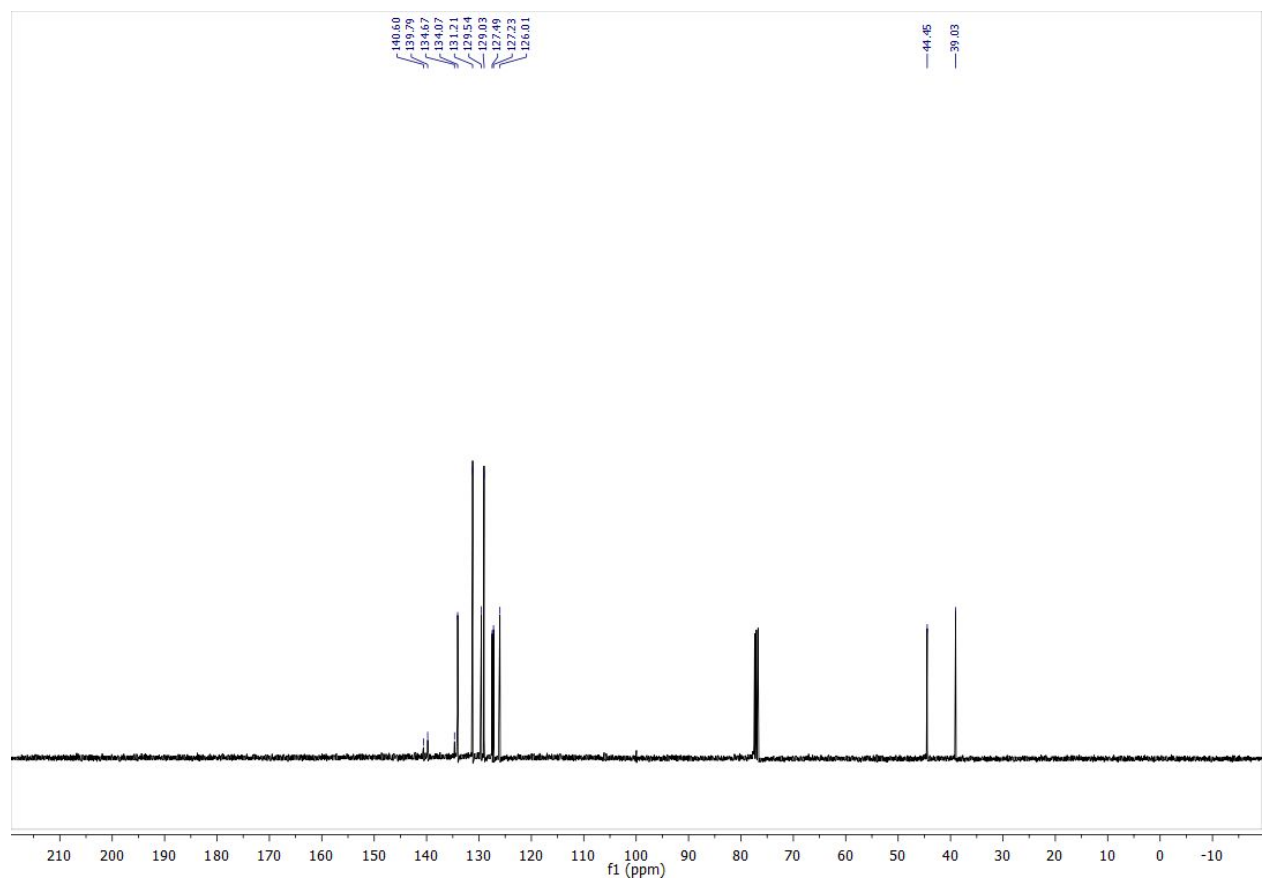

${ }^{13} \mathrm{C}\left\{{ }^{1} \mathrm{H}\right\} \mathrm{NMR}\left(\mathrm{CDCl}_{3}, 100.6 \mathrm{MHz}\right)$ spectrum of (3-(methylsulfonyl)benzyl)(phenyl)sulfane 15 


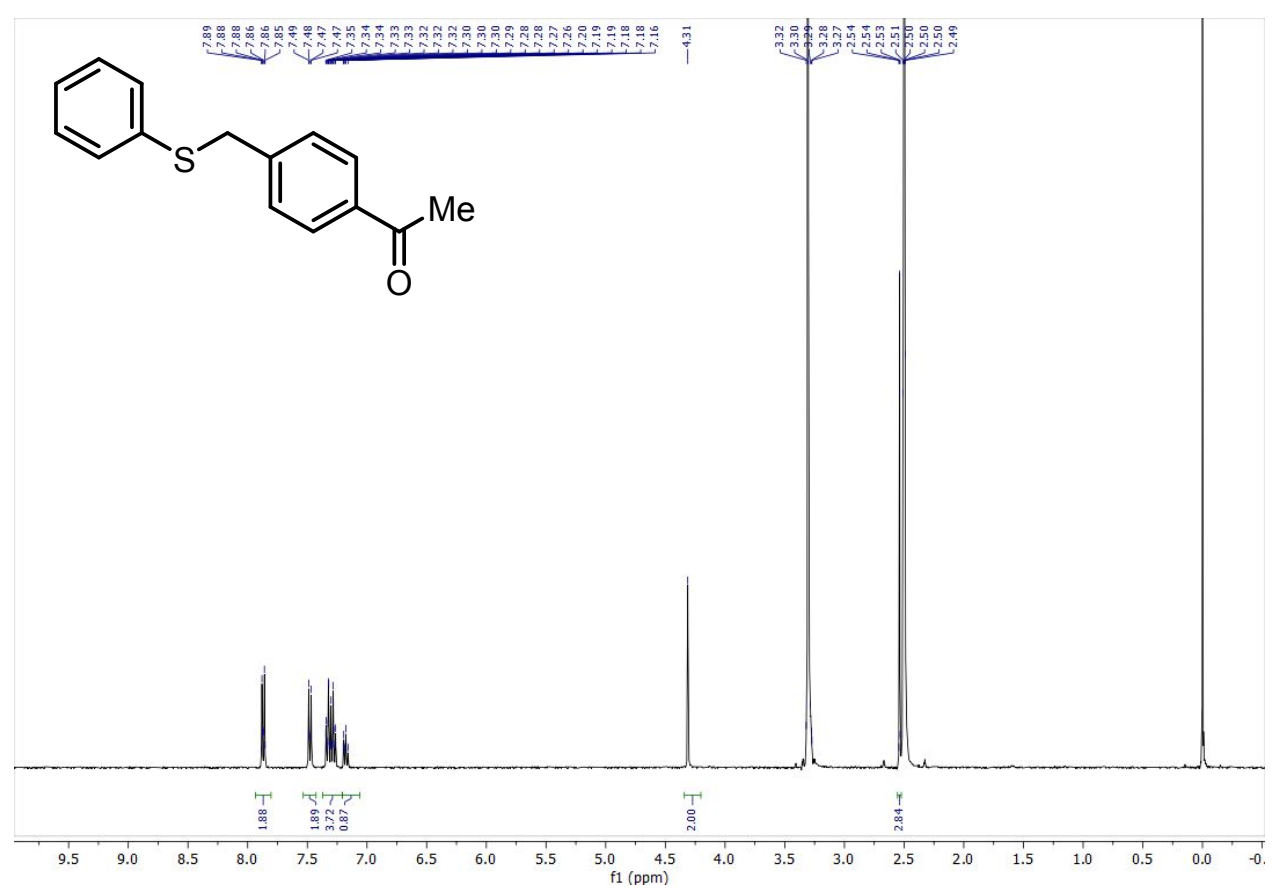

${ }^{1} \mathrm{H}$ NMR (DMSO- $\left.d_{6}, 400 \mathrm{MHz}\right)$ spectrum of 1-(4-((phenylthio)methyl)phenyl)ethan-1-one 16

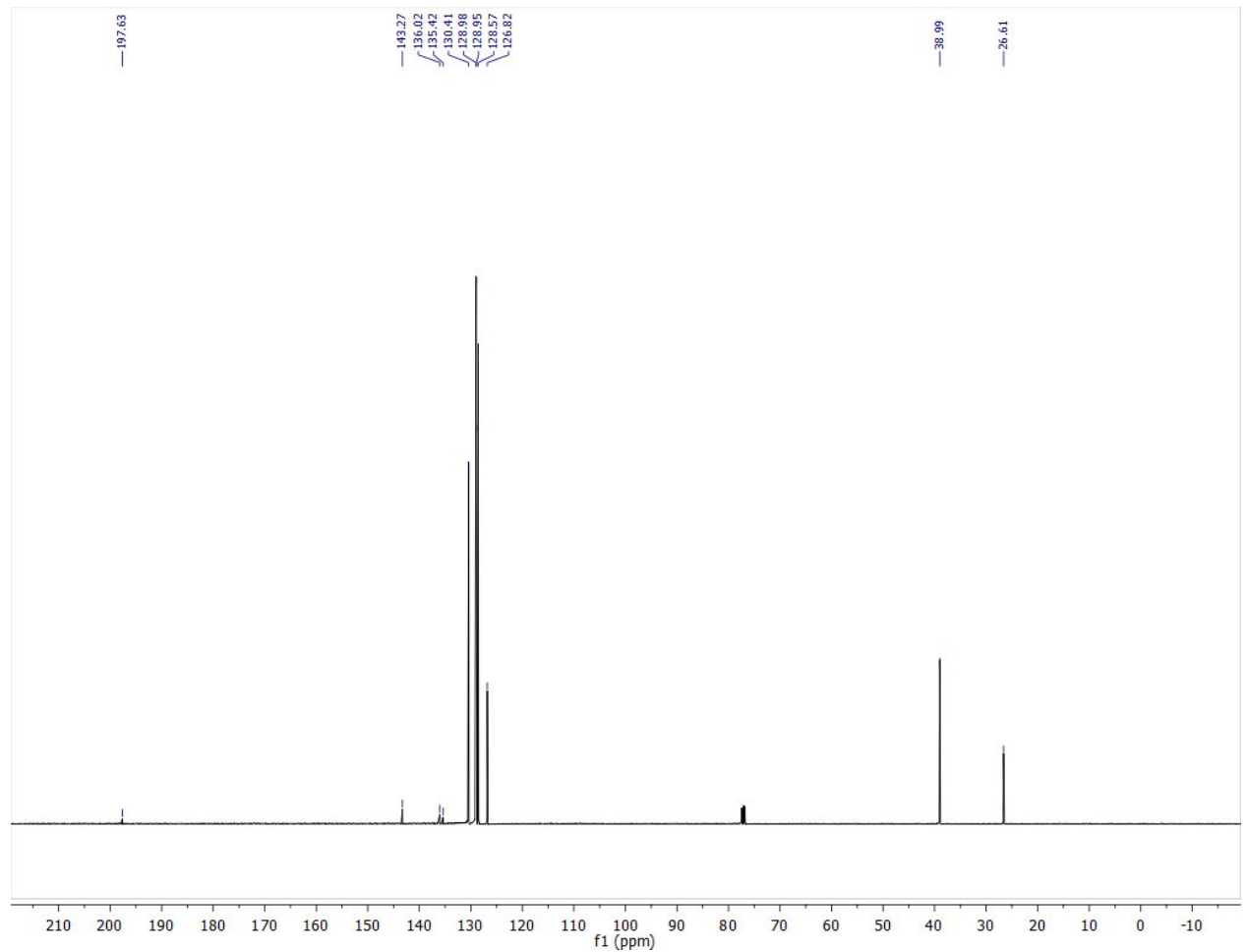

${ }^{13} \mathrm{C}\left\{{ }^{1} \mathrm{H}\right\}$ NMR $\left(\mathrm{CDCl}_{3}, 100.6 \mathrm{MHz}\right)$ spectrum of 1-(4-((phenylthio)methyl)phenyl)ethan-1-one 16 


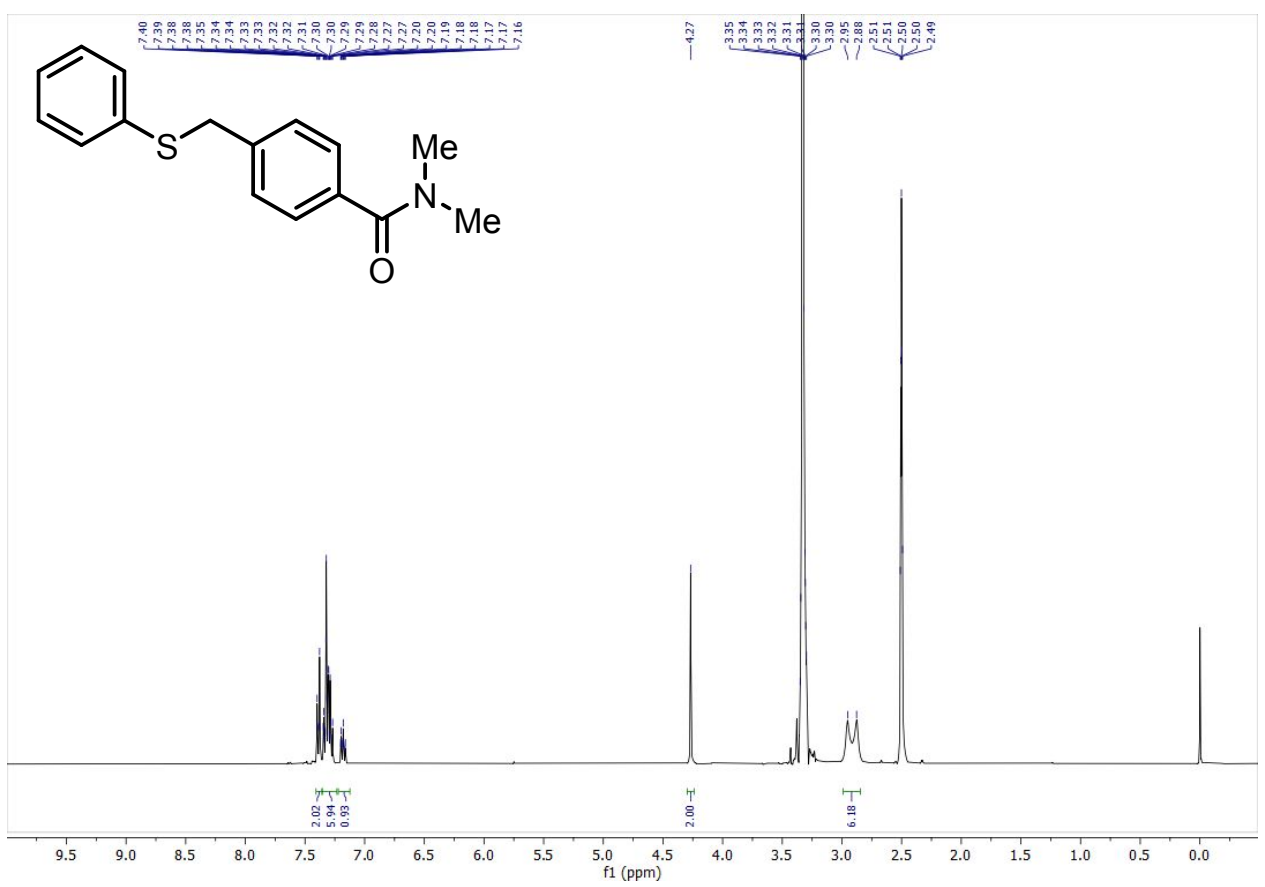

${ }^{1} \mathrm{H}$ NMR (DMSO- $\left.d_{6}, 400 \mathrm{MHz}\right)$ spectrum of $N, N$-dimethyl-4-((phenylthio)methyl)benzamide 17

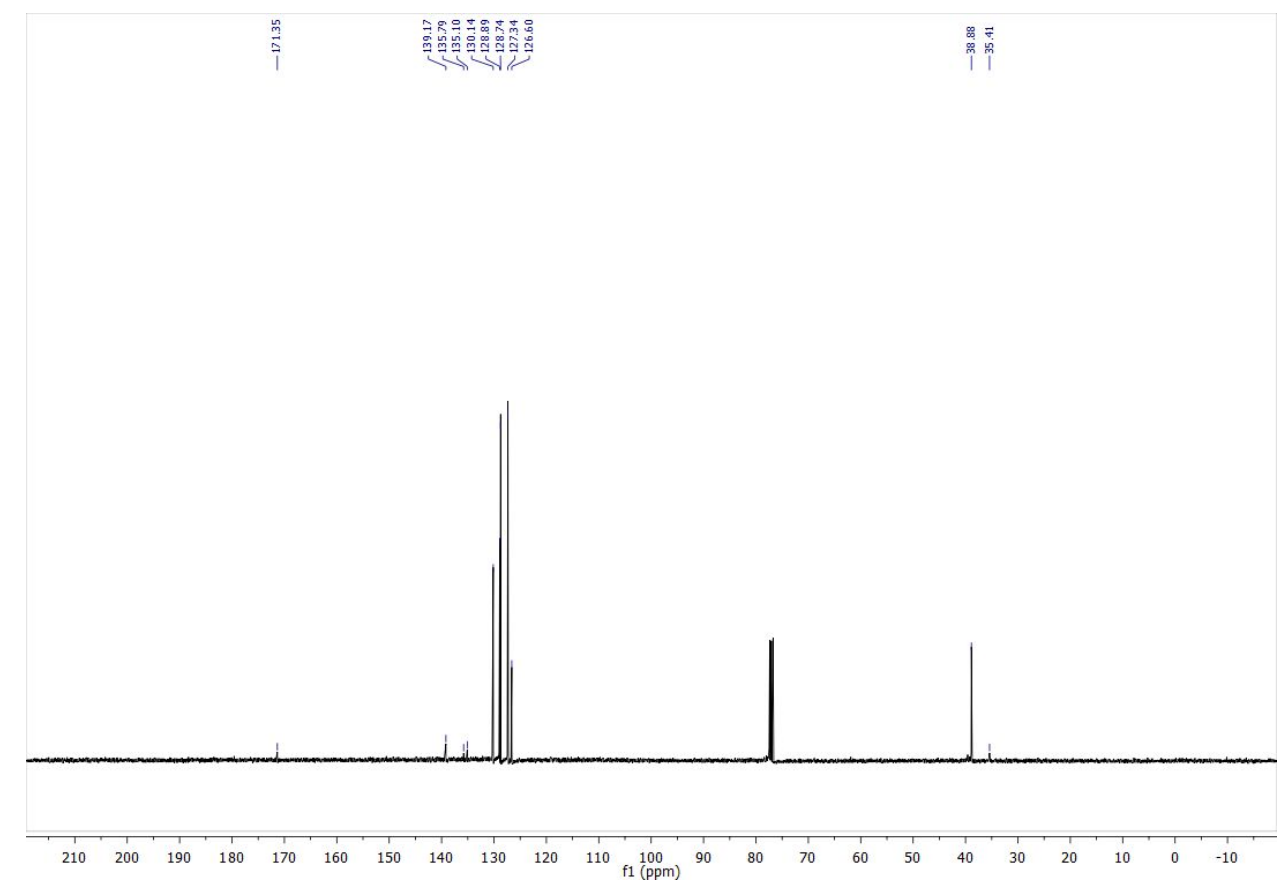

${ }^{13} \mathrm{C}\left\{{ }^{1} \mathrm{H}\right\}$ NMR $\left(\mathrm{CDCl}_{3}, 100.6 \mathrm{MHz}\right)$ spectrum of $N, N$-dimethyl-4-((phenylthio)methyl)benzamide 17 


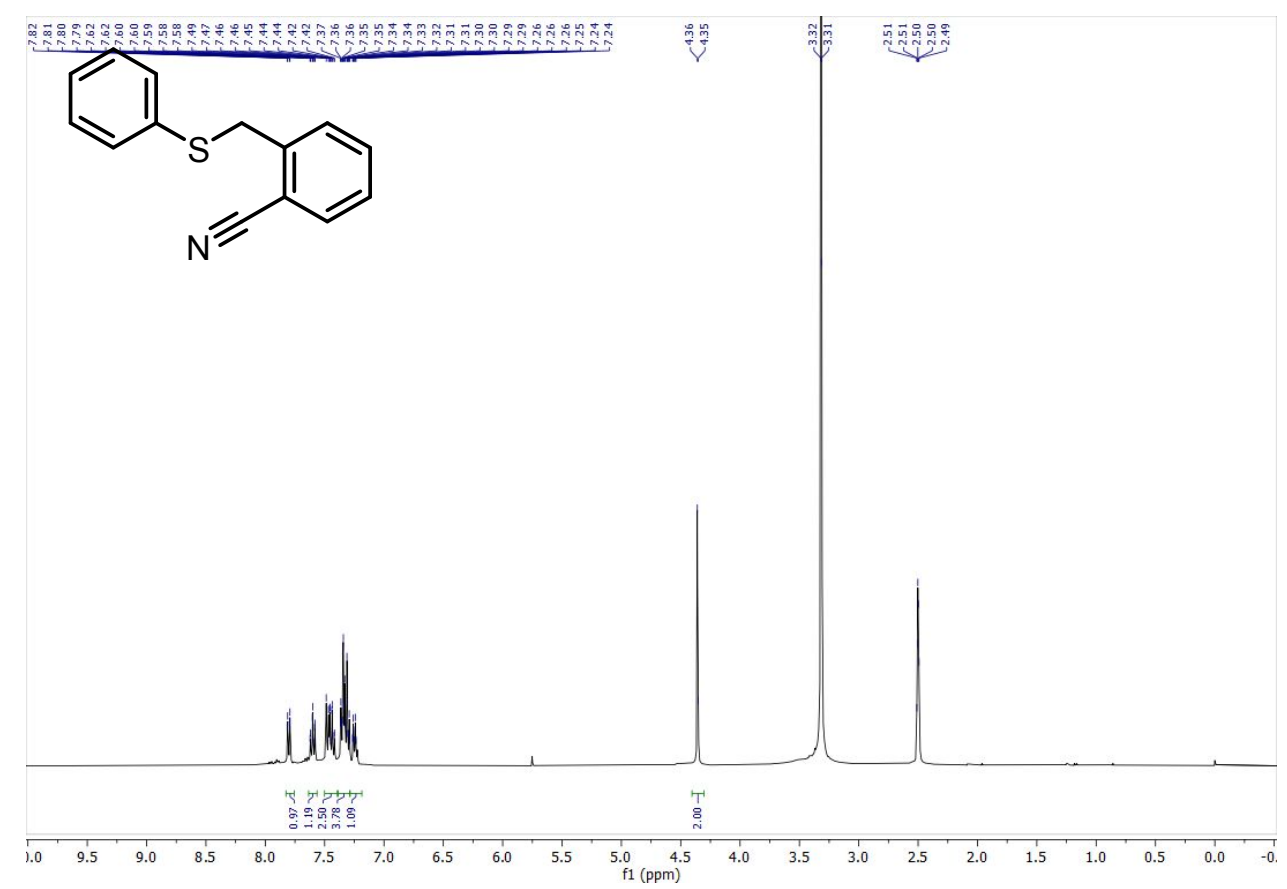

${ }^{1} \mathrm{H}$ NMR (DMSO- $\left.d_{6}, 400 \mathrm{MHz}\right)$ spectrum of 2-((phenylthio)methyl)benzonitrile 18

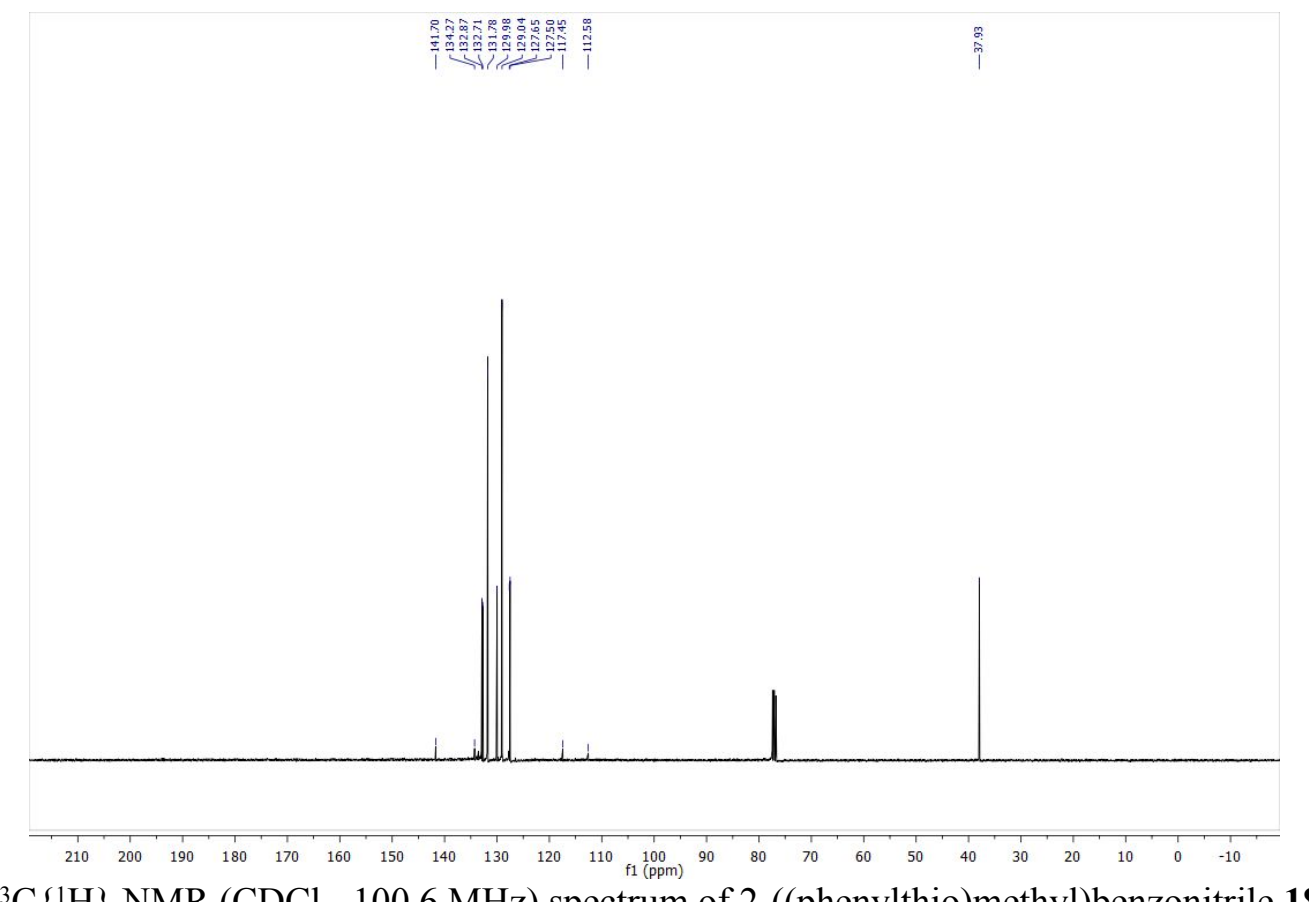




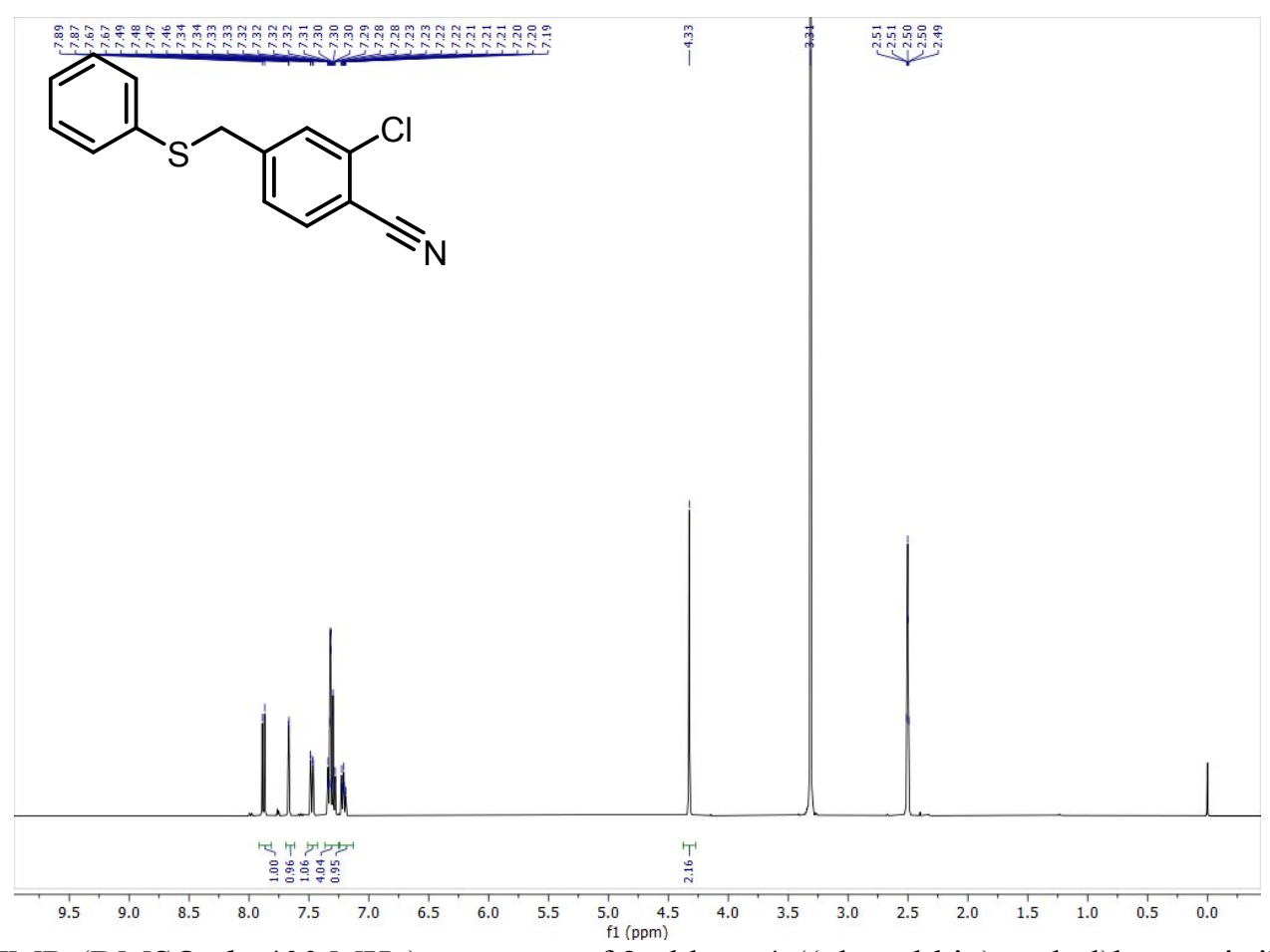

${ }^{1} \mathrm{H}$ NMR (DMSO- $d_{6}, 400 \mathrm{MHz}$ ) spectrum of 2-chloro-4-((phenylthio)methyl)benzonitrile 19

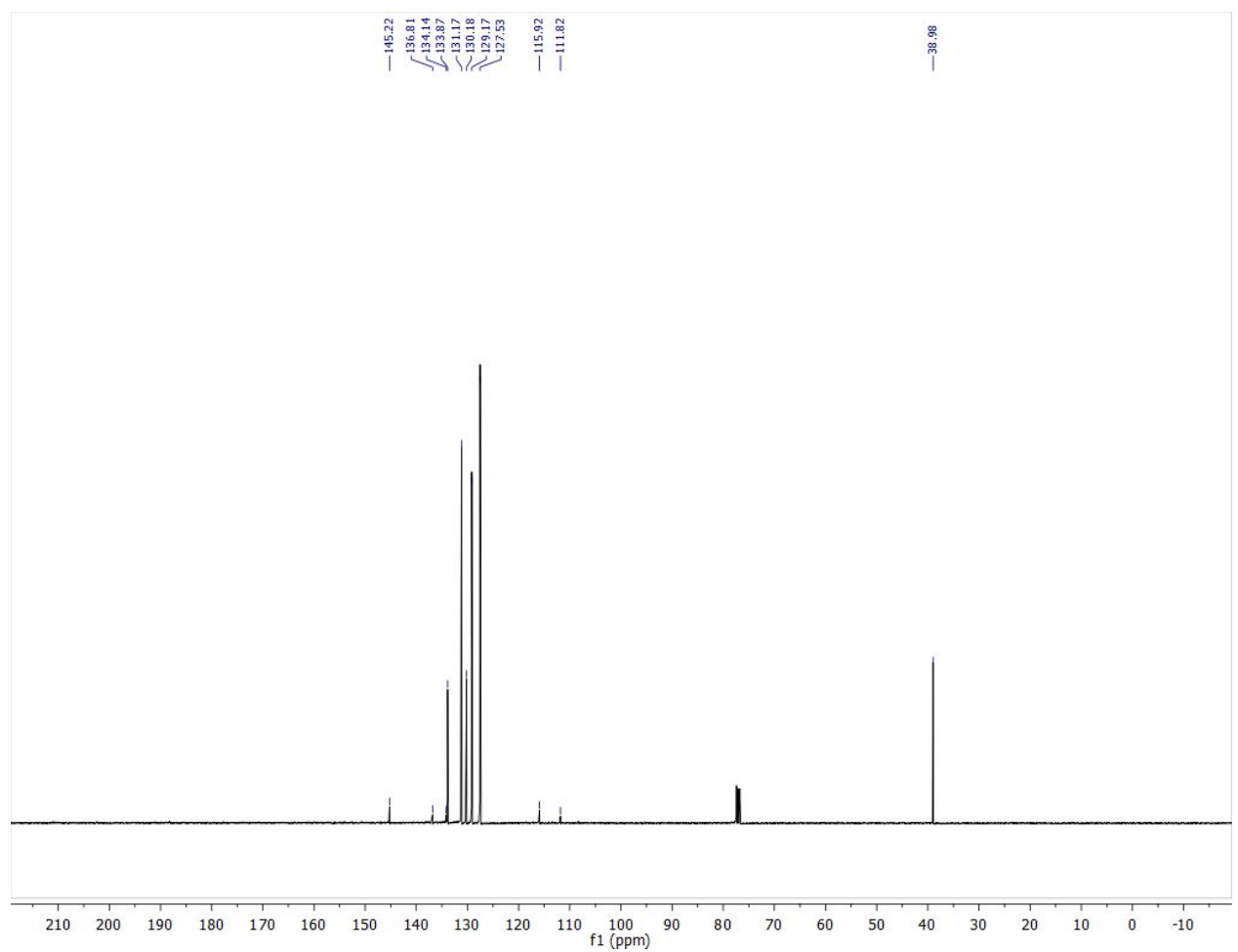

${ }^{13} \mathrm{C}\left\{{ }^{1} \mathrm{H}\right\} \mathrm{NMR}\left(\mathrm{CDCl}_{3}, 100.6 \mathrm{MHz}\right)$ spectrum of 2-chloro-4-((phenylthio)methyl)benzonitrile 19 


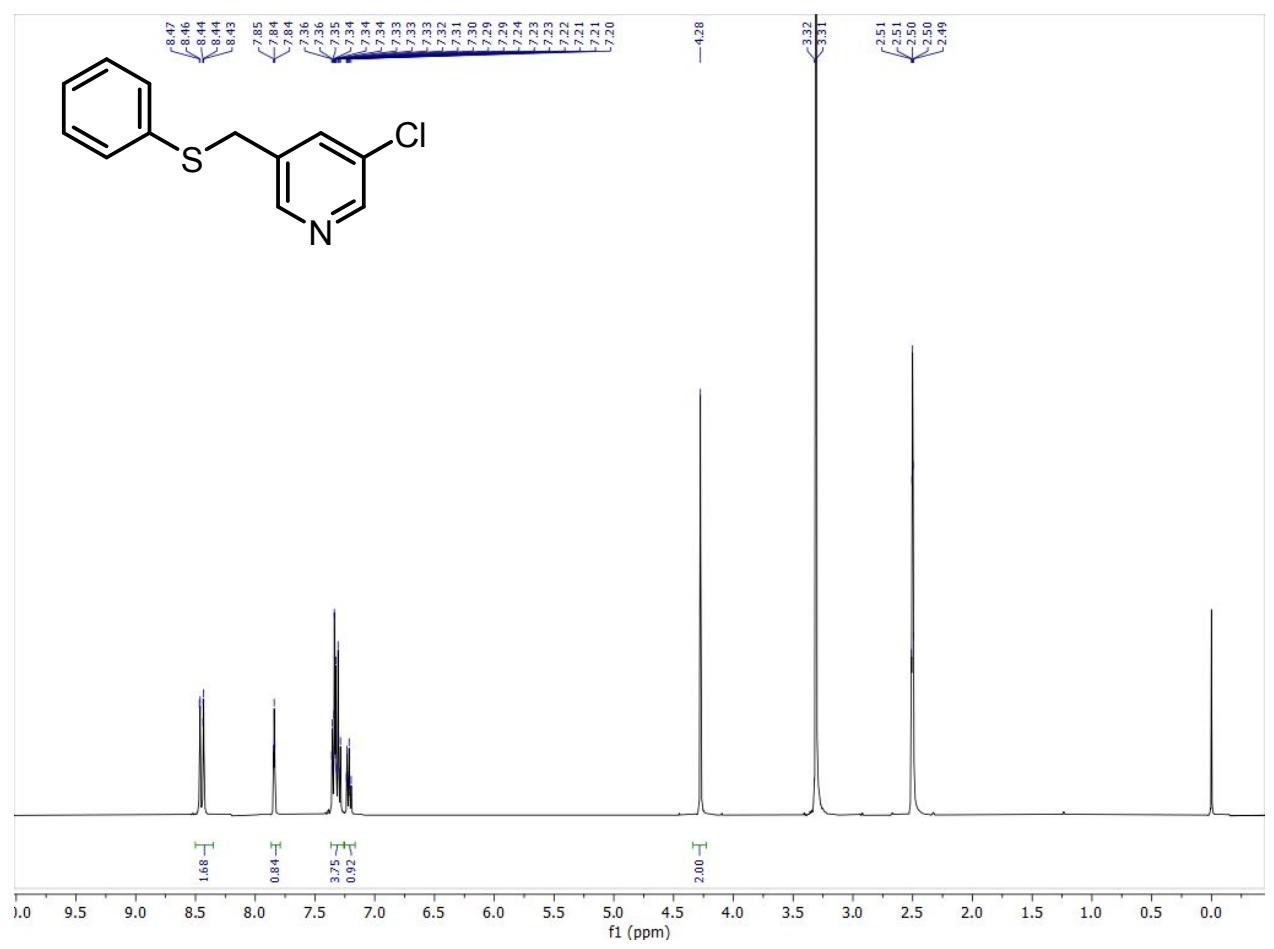

${ }^{1} \mathrm{H}$ NMR (DMSO- $d_{6}, 400 \mathrm{MHz}$ ) spectrum of 3-chloro-5-((phenylthio)methyl)pyridine 20
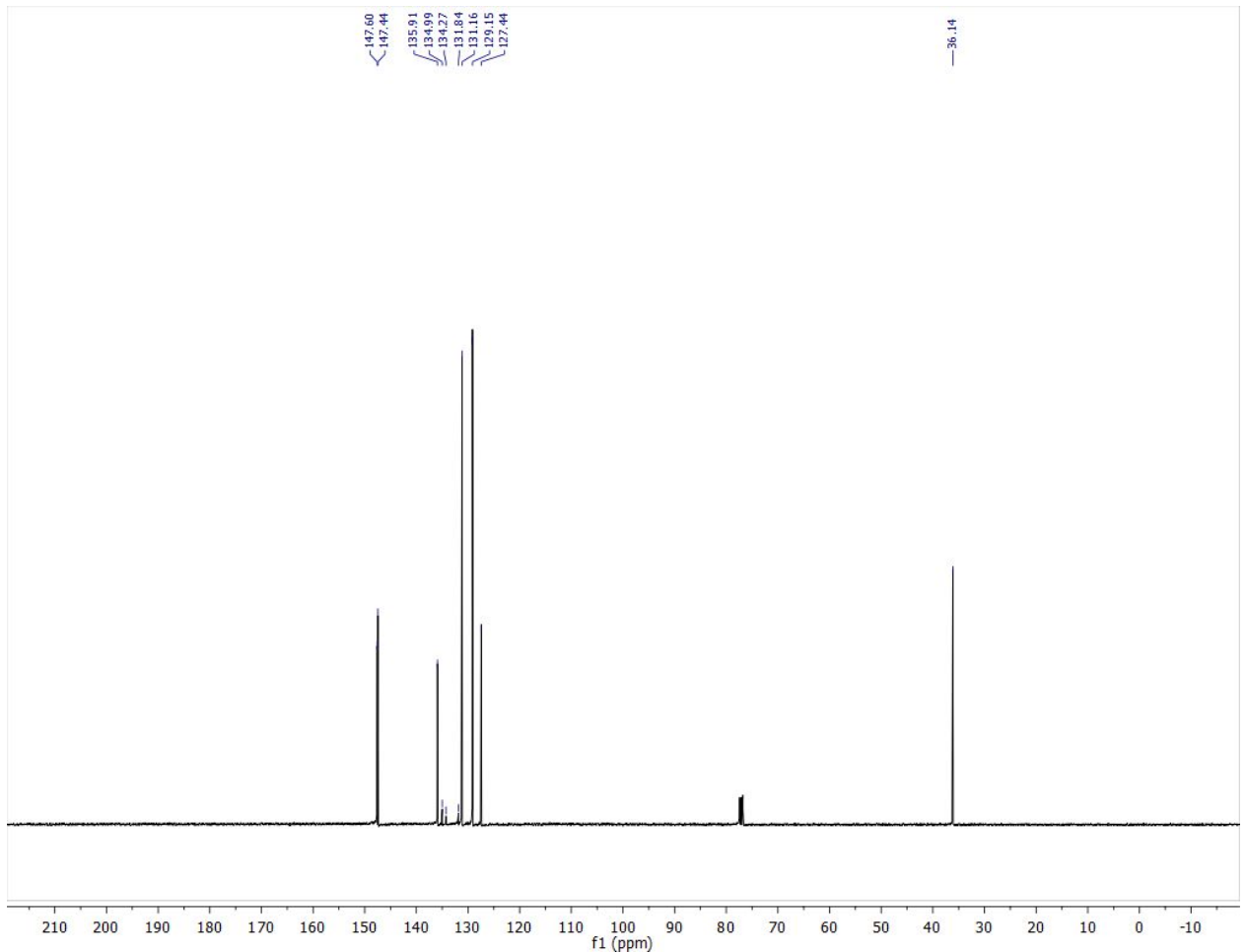

${ }^{13} \mathrm{C}\left\{{ }^{1} \mathrm{H}\right\} \mathrm{NMR}\left(\mathrm{CDCl}_{3}, 100.6 \mathrm{MHz}\right)$ spectrum of 3-chloro-5-((phenylthio)methyl)pyridine 20 


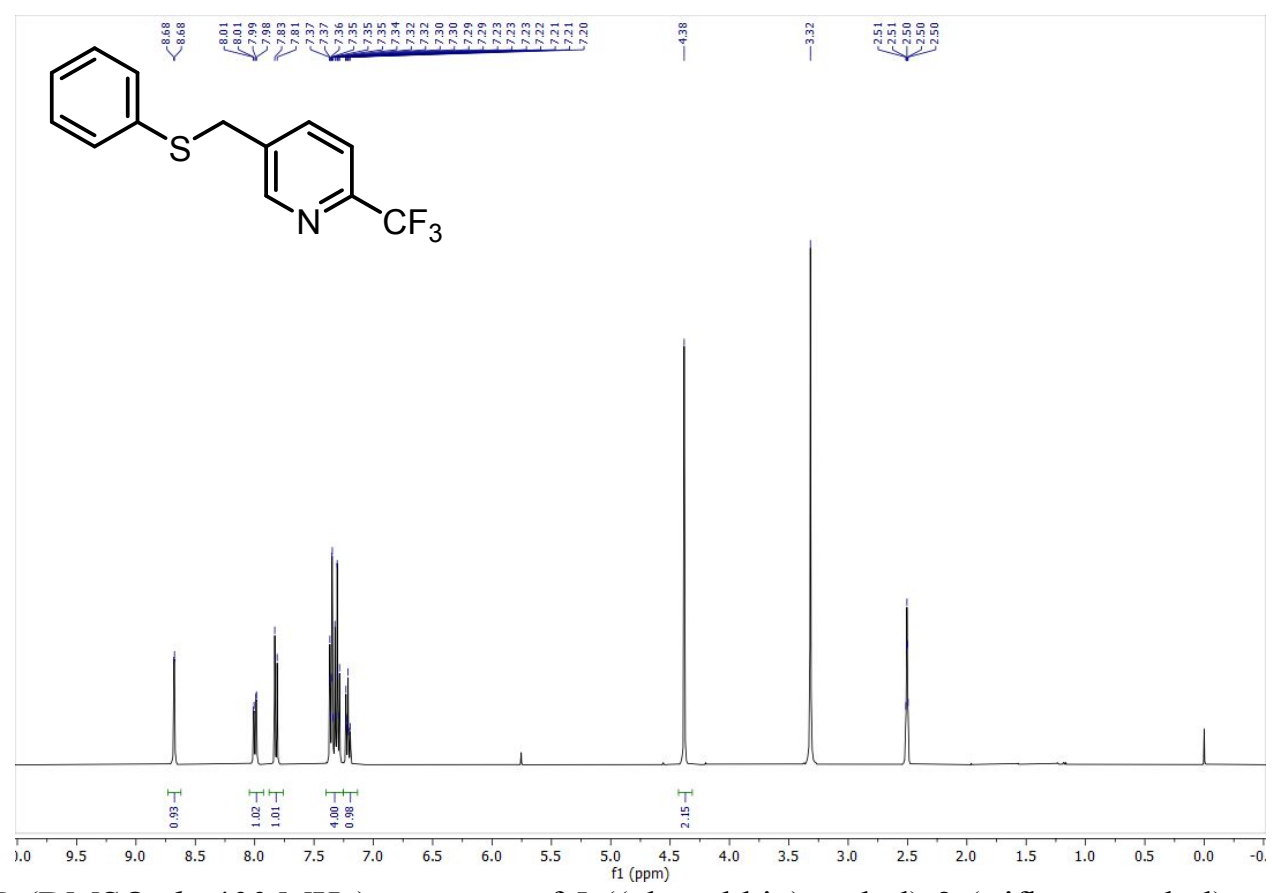

${ }^{1} \mathrm{H}$ NMR (DMSO- $d_{6}, 400 \mathrm{MHz}$ ) spectrum of 5-((phenylthio)methyl)-2-(trifluoromethyl)pyridine 21

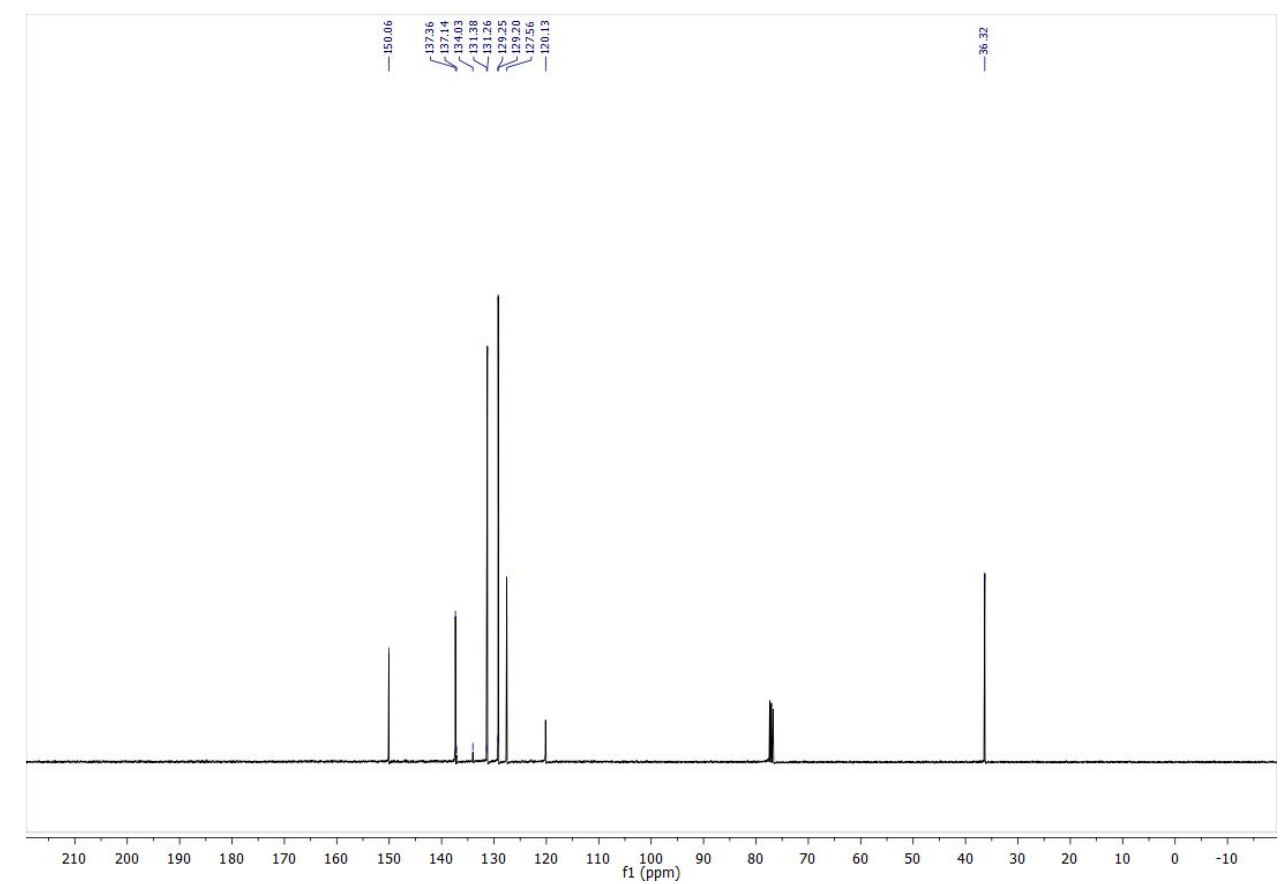

${ }^{13} \mathrm{C}\left\{{ }^{1} \mathrm{H}\right\}$ NMR $\left(\mathrm{CDCl}_{3}, 100.6 \mathrm{MHz}\right)$ spectrum of 5-((phenylthio)methyl)-2-(trifluoromethyl)pyridine 21 


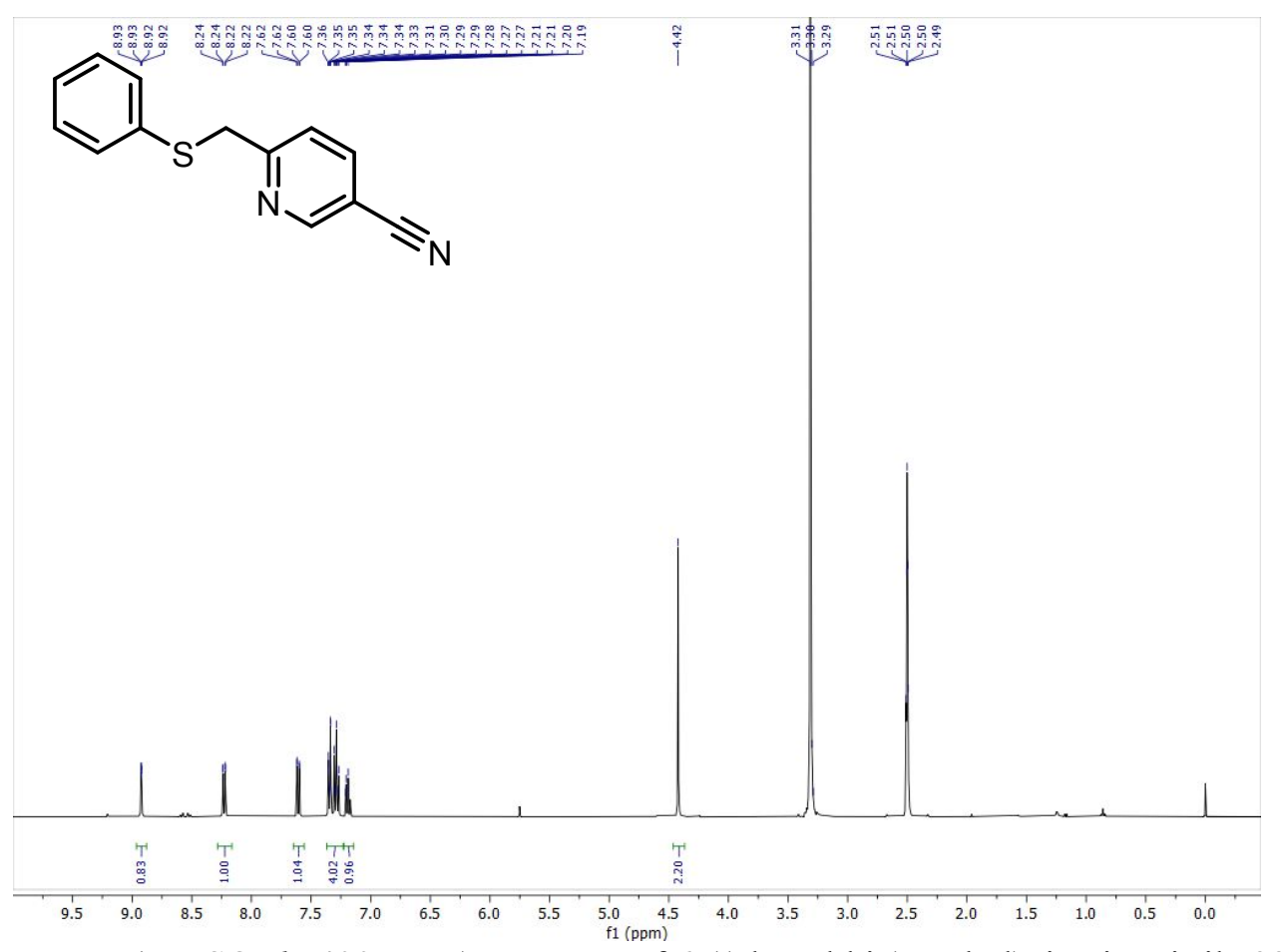

${ }^{1} \mathrm{H}$ NMR (DMSO- $\left.d_{6}, 400 \mathrm{MHz}\right)$ spectrum of 6-((phenylthio)methyl)nicotinonitrile 22

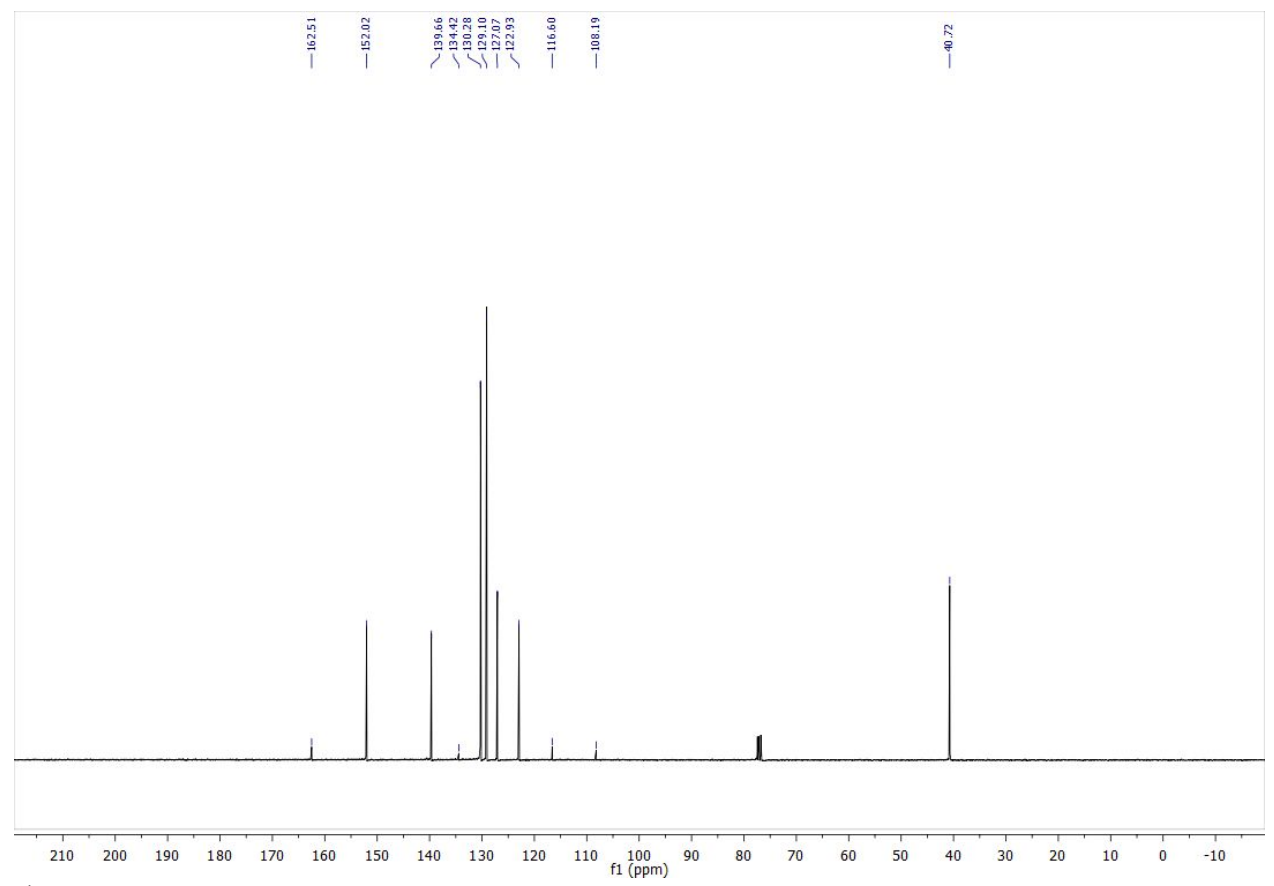

${ }^{13} \mathrm{C}\left\{{ }^{1} \mathrm{H}\right\}$ NMR $\left(\mathrm{CDCl}_{3}, 100.6 \mathrm{MHz}\right)$ spectrum of 6-((phenylthio)methyl)nicotinonitrile 22 


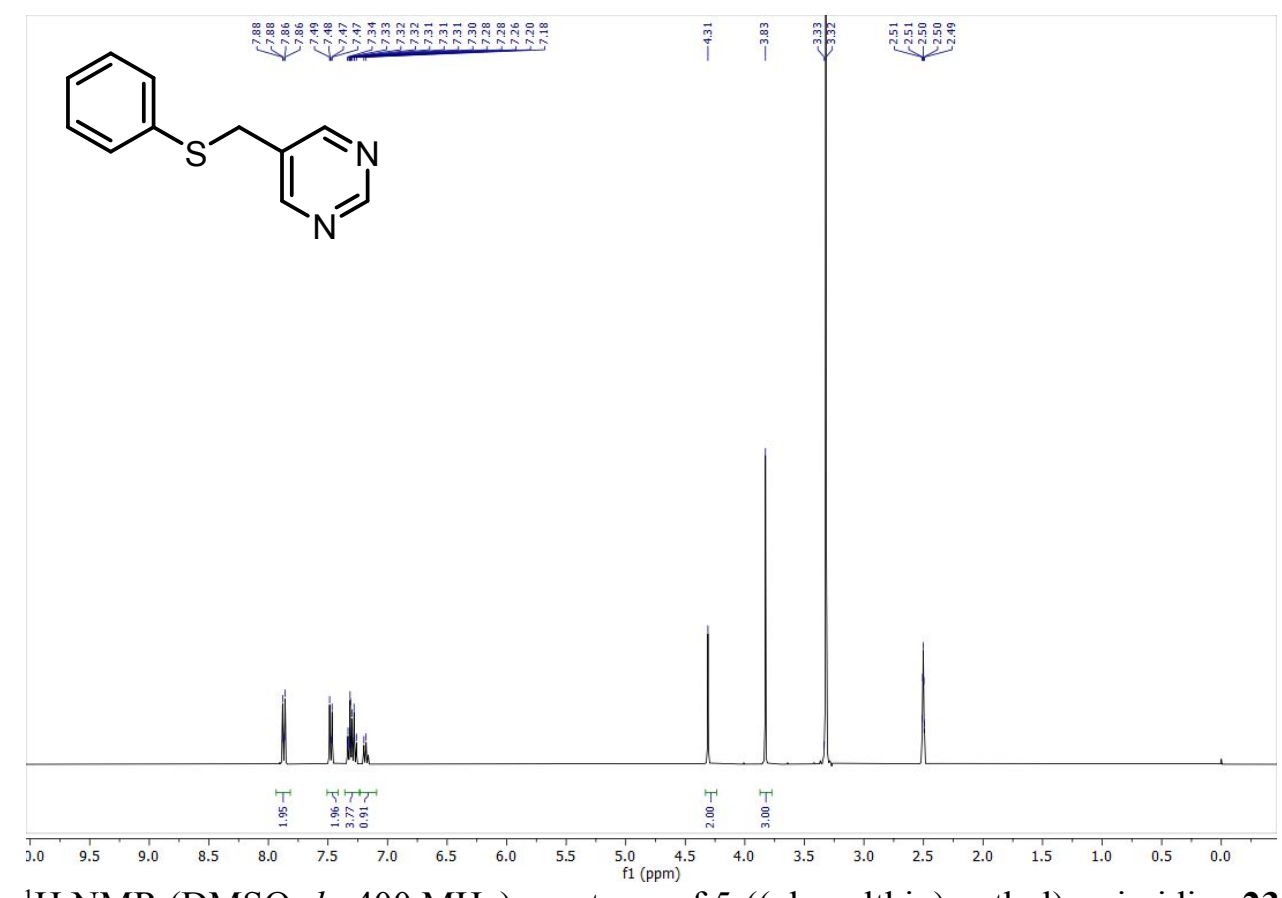

${ }^{1} \mathrm{H}$ NMR (DMSO- $\left.d_{6}, 400 \mathrm{MHz}\right)$ spectrum of 5-((phenylthio)methyl)pyrimidine 23

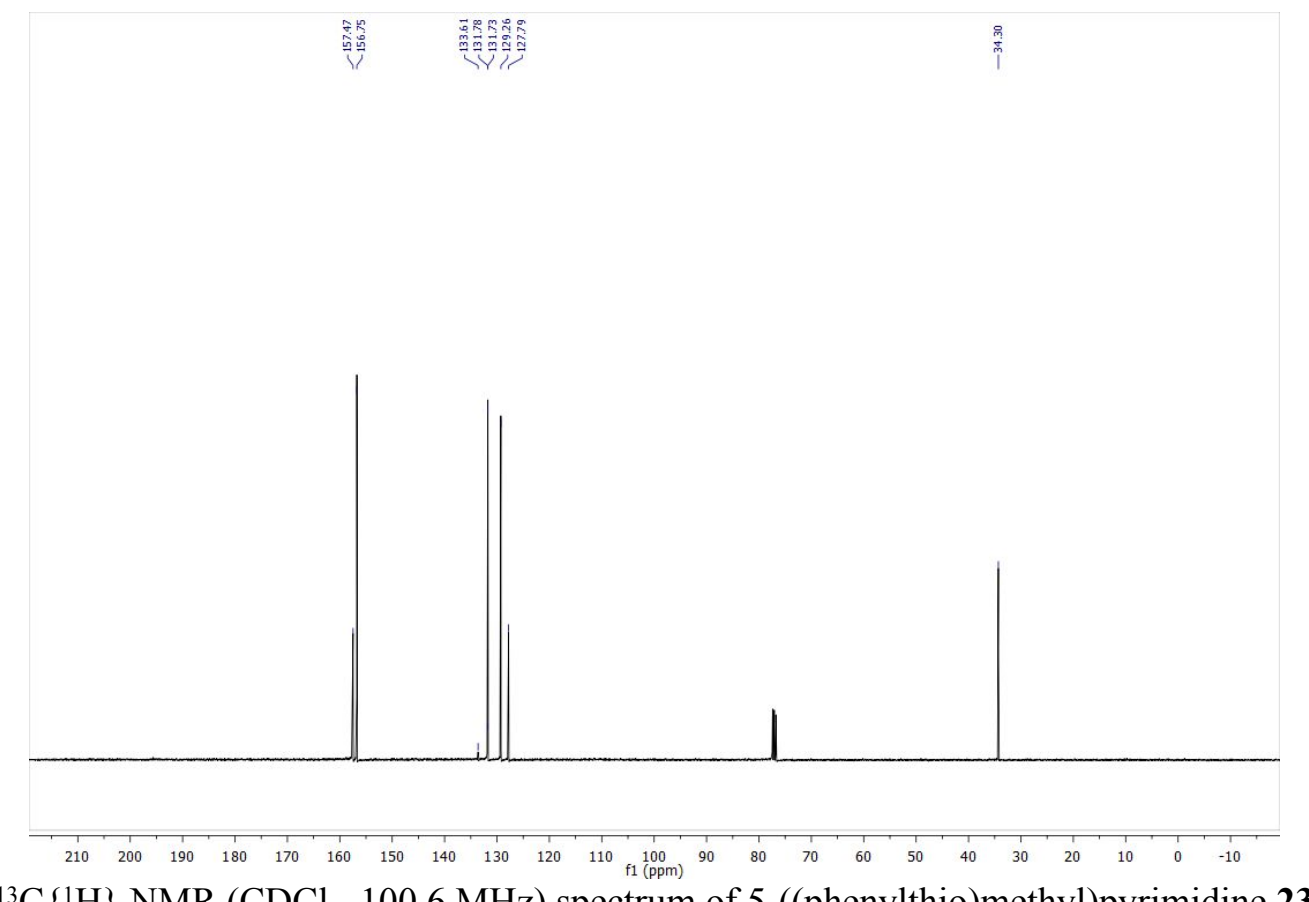

